\title{
Lactate in the Regulation of Tumor Microenvironment and Therapeutic Approaches
}

\author{
Karen G. de la Cruz-López ${ }^{1,2,3}$, Leonardo Josué Castro-Muñoz ${ }^{1,2}$, \\ Diego O. Reyes-Hernández ${ }^{4,5}$, Alejandro García-Carrancá ${ }^{2,3}$ and \\ Joaquín Manzo-Merino ${ }^{2,5,6 *}$
}

${ }^{1}$ Programa de Doctorado en Ciencias Biomédicas, Instituto de Investigaciones Biomédicas, Universidad Nacional Autónoma de México, Ciudad Universitaria, Mexico City, Mexico, ${ }^{2}$ Unidad de Investigación Biomédica en Cáncer, Instituto Nacional de Cancerología, México/Instituto de Investigaciones Biomédicas, Universidad Nacional Autónoma de México, Mexico City, Mexico, ${ }^{3}$ Laboratory of Virus and Cancer, Subdirección de Investigación Básica, Instituto Nacional de Cancerología, Mexico City, Mexico, ${ }^{4}$ Programa de Maestría y Doctorado en Ciencias Médicas, Odontológicas y de la Salud, Maestría en Investigación Clínica Experimental, Universidad Nacional Autónoma de Mexico, Mexico City, Mexico, ${ }^{5}$ Biological Cancer Causing Agents Group, Instituto Nacional de Cancerología, Mexico City, Mexico, ${ }^{6}$ Cátedras CONACyT-Instituto Nacional de Cancerología, Mexico City, Mexico

OPEN ACCESS

Edited by:

Nadia Judith Jacobo-Herrera Instituto Nacional de Ciencias Médicas y Nutrición Salvador Zubirán (INCMNSZ), Mexico

Reviewed by: Michael P. Lisanti, University of Salford, United Kingdom Liwei Lang, Augusta University, United States

*Correspondence: Joaquín Manzo-Merino jmanzome@conacyt.mx

Specialty section: This article was submitted to

Cancer Metabolism, a section of the journal

Frontiers in Oncology

Received: 17 August 2019

Accepted: 15 October 2019

Published: 01 November 2019

Citation:

de la Cruz-López KG

Castro-Muñoz LJ,

Reyes-Hernández DO,

García-Carrancá A and

Manzo-Merino J (2019) Lactate in the

Regulation of Tumor

Microenvironment and Therapeutic

Approaches. Front. Oncol. 9:1143.

doi: 10.3389/fonc. 2019.01143
Tumor cells must generate sufficient ATP and biosynthetic precursors in order to maintain cell proliferation requirements. Otto Warburg showed that tumor cells uptake high amounts of glucose producing large volumes of lactate even in the presence of oxygen, this process is known as "Warburg effect or aerobic glycolysis." As a consequence of such amounts of lactate there is an acidification of the extracellular $\mathrm{pH}$ in tumor microenvironment, ranging between 6.0 and 6.5. This acidosis favors processes such as metastasis, angiogenesis and more importantly, immunosuppression, which has been associated to a worse clinical prognosis. Thus, lactate should be thought as an important oncometabolite in the metabolic reprogramming of cancer. In this review, we summarized the role of lactate in regulating metabolic microenvironment of cancer and discuss its relevance in the up-regulation of the enzymes lactate dehydrogenase (LDH) and monocarboxilate transporters (MCTs) in tumors. The goal of this review is to expose that lactate is not only a secondary product of cellular metabolic waste of tumor cells, but also a key molecule involved in carcinogenesis as well as in tumor immune evasion. Finally, the possible targeting of lactate production in cancer treatment is discussed.

Keywords: lactate, acidification, tumor microenvironment (TME), therapy, immune response

\section{INTRODUCTION}

Cellular transformation involves the deregulated control of cell proliferation, resistance to cell death, immune evasion and circumvention of growth suppressor activities, which finally allow cancer establishment (1). Additionally, it has been observed that tumor cells have the remarkable ability to adjust their energetic metabolism as part of their mechanisms for tumor survival, this feature is now recognized as a hallmark of cancer (2). The increased metabolic rate in several neoplasms, was first studied by Otto Warburg in 1926 demonstrating that tumor cells uptake high amounts of glucose as a primary energy source, producing excessive amounts of lactate, even in the presence of oxygen (3). In 1972, Efraim Racker named such effect as the "Warburg Effect," also 
known as "aerobic glycolysis" (4). Initially, it was proposed that the driving event of the enhanced glycolysis in tumor cells was caused by an irreversible damage of the mitochondrial function. Although defects in mitochondria function have been shown in some types of cancer (5), this process alone cannot explain the metabolic preference of tumor cells.

The Warburg phenotype is present in several neoplasms including breast, colon, cervical and liver cancer (6-9). The increased glucose uptake and metabolism by neoplastic cells represents the basis for tumor detection using positron emission tomography (PET); PET imaging uses a radioisotope-labeled glucose tracer, ${ }^{18} \mathrm{~F}$-fluorodeoxyglucose $\left({ }^{18} \mathrm{~F}\right.$-FDG), to identify areas of high glucose uptake/metabolism in the body. After ${ }^{18} \mathrm{~F}-$ FDG distribution, the radionuclide is transported into the cells by glucose transporters, and consequently phosphorylated by the hexokinase to produce ${ }^{18} \mathrm{~F}-\mathrm{FDG}-6$-phosphate $\left({ }^{18} \mathrm{~F}-\mathrm{FDG}-6\right.$ p). Once inside the cell, the ${ }^{18}$ F-FDG-6-p accumulates in the cytoplasm since this molecule cannot be further metabolized through the glycolytic pathway because it lacks the necessary 2 'hydroxyl group (10). Additionally, due to its highly polar nature the ${ }^{18}$ F-FDG-6-p is trapped inside the cell, thus the accumulated amounts of ${ }^{18}$ F-FDG-6-p are used to identify the presence of solid tumors as well as the effectiveness of treatments (10).

The Warburg effect involves the alteration of metabolic enzymes, including hexokinase 2 (HK2), pyruvate kinase type M2 (PKM2), glucose transporter 1 (GLUT1), lactate dehydrogenase $(\mathrm{LDH})$ and lactate transporters (monocarboxilate transporters [MCTs]) (11-14). Importantly, the Warburg phenotype has been associated, not only with an increased obtention of energy but also with the activation of numerous transcription factors, such as $\mathrm{c}-\mathrm{Myc}$, NF- $\mathrm{kB}$, and Hypoxia-Inducible Factor 1- $\alpha$ (HIF 1- $\alpha$ ) (15-17). These transcription factors can regulate the expression of metabolic enzymes resulting in the deregulated conversion of glucose to lactate (18) then promoting a "tumor lactagenesis" state (19).

Glycolysis is by far less efficient than oxidative phosphorylation for ATP production, and for this reason cancer cells increase their glucose uptake and glycolytic rate. The high utilization of glucose by cancer cells results in the accumulation of extracellular lactate affecting a number of cell types within the tumor microenvironment (TME), composed by a variety of different cell types such as endothelial cells, cancerassociated fibroblasts (CAFs), immune cells and non-cancer stroma cells (20).

For a long time, lactate was only recognized as a "metabolic waste product" derived of aerobic glycolysis, however, it has now been firmly demonstrated that lactate can be incorporated into the tricarboxylic acid (TCA) cycle and be a source of energy, and even act as an oncometabolite with signaling properties. In this review we describe the role of lactate in tumor progression, highlighting its ability to promote invasion and metastasis. We also show the role of lactate as a metabolic fuel for tumor cells, as well as its participation in drug resistance (Figure 1). The importance of the suppressive acidic tumor microenvironment induced by lactate is also presented. Finally, we discuss the possible targeting of lactate production as a novel therapeutic approach.

\section{LACTATE METABOLISM BOTH IN NORMAL PHYSIOLOGY AND CANCER}

Lactate (2-hydroxypropanoic acid) is a hydroxycarboxylic acid that may exist in the human body as two stereoisomers, Dlactate and L-lactate; the latter is the predominant physiological enantiomer of lactate (21). D-lactate is also present but generally accounts only for $1-5 \%$ of L-lactate concentration (22), in this review we only focus in L-lactate, designed as lactate. The $\mathrm{pKa}$ of the lactate/lactic acid pair is 3.8 at physiological $\mathrm{pH}$, the lactic acid dissociates immediately into lactate (base form) and hydrogen $\left(\mathrm{H}^{+}\right)(22,23)$. Under physiological conditions, lactate is used as a fuel source by the heart, brain and skeletal muscle (24); it can also be converted into glucose in the liver by the Cori cycle, serving as an alternate source of energy (25). Also, lactate acts as an inter-organ carbon shuttle, supplying both aerobic metabolism and gluconeogenesis pathways (26), in fact, now this is identified as a "lactate shuttle theory," describing that lactate, under fully aerobic conditions can transcend compartment barriers and shuttle occur within and among cells, tissues and organs (27-29), interestingly, this phenomenon is also observed in cancer, and will be described in this review.

The physiological concentration of lactate, in blood and

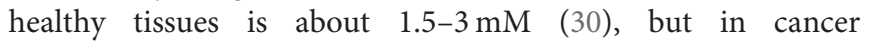
tissues it can be present in up to $10-30 \mathrm{mM}$ concentrations (31). Table 1 summarizes the amounts of lactate in different neoplasms.

Glucose is the major source of lactate production in most solid tumors (39). This molecule is an essential metabolic energy source for all living organisms and the structural precursor for cellular biosynthesis of proteins, lipids, and nucleic acids with ATP generation being the essential metabolic process for energy supply to the cells. Mammalian cells generate their ATP through glycolysis in the cytoplasm (2 ATP per glucose molecule) and oxidative phosphorylation (OXPHOS) in the mitochondria (32-34 ATP per glucose molecule). Normal cells (except erythrocytes and skeletal muscle cells during high intensity exercise) depend on OXPHOS for ATP production from glucose; on the contrary, cancer cells obtain their ATP by glycolysis and the final conversion of glucose to lactate (40).

Additionally, it has been demonstrated that glutamine may contribute to a small amount of lactate formation in tumor cells (41). Glutamine comprise the most abundant amino acid in blood circulation (about $500 \mu \mathrm{M}$ ), representing more than $20 \%$ of the free amino acid pool in blood and $40 \%$ in muscle (42). It was demonstrated that tumor cells require at least 10 times as much glutamine as any other amino acid in culture (43). In the mitochondrion, glutamine is deaminated to glutamate by glutaminase (GLS), later in other deamination reaction, $\alpha$-ketoglutarate is generated by the enzyme glutamate dehydrogenase (GDH) finally incorporated into TCA cycle to generate malate by fumarase enzyme since $\alpha$-ketoglutarate is the major anaplerotic source for TCA cycle (44). Malate is exported to the cytosol where is it converted to pyruvate by the malic enzyme which is finally converted to lactate by LDHA (41). 


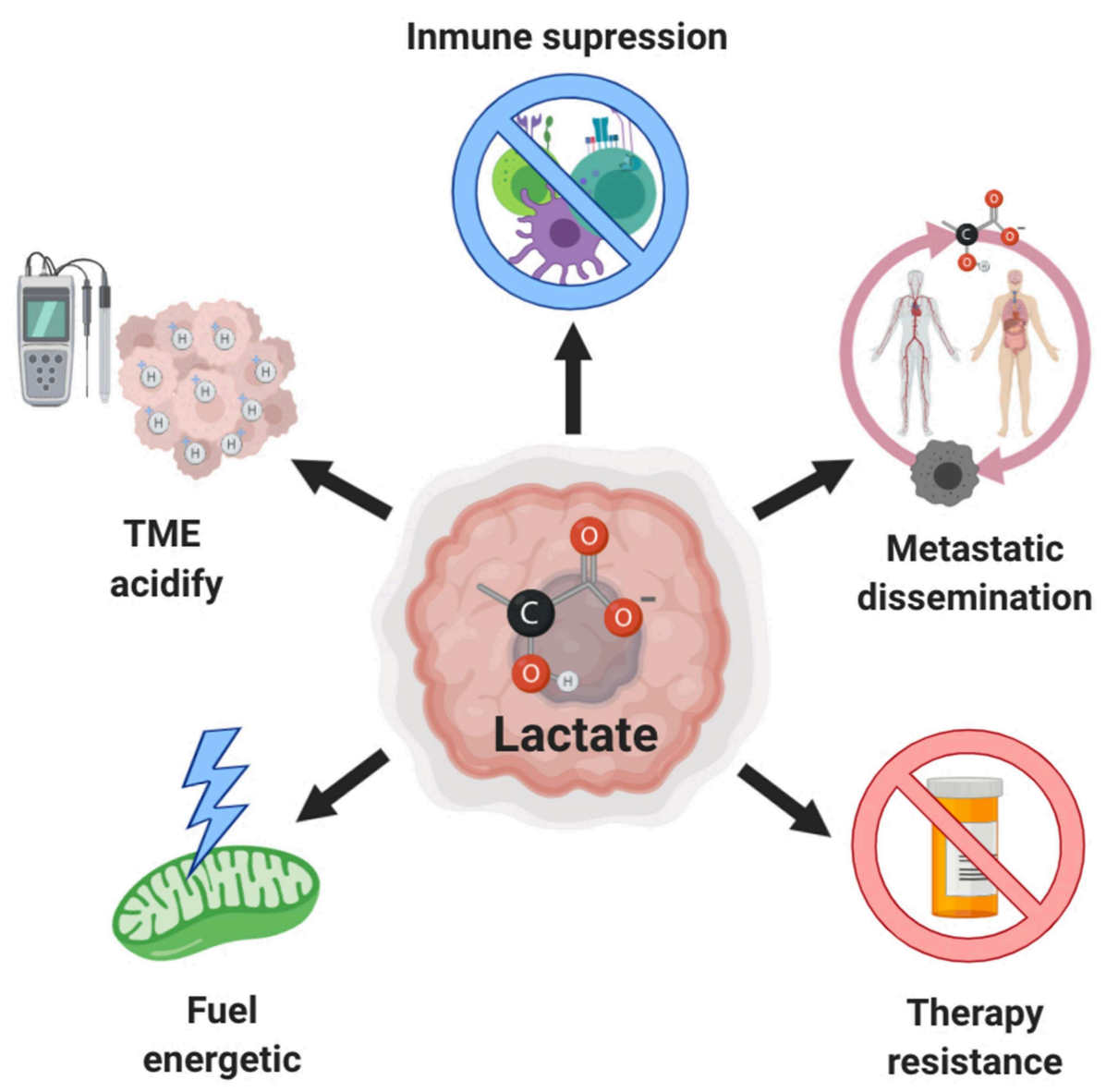

FIGURE 1 | Role of lactate in cancer. Excessive production of lactate by both, tumor and stromal cells, is associated with increased aggressiveness due to the extracellular acidification that also induces invasion and metastasis, inhibition of the antitumor immune response and resistance to therapy. Moreover, this lactate can be used as an alternative source of fuel by tumor cells.

\section{LACTATE AS A FUEL SOURCE FOR CANCER CELLS}

Despite lactate was first recognized only as a waste product of anaerobic cell metabolism, it is now known that lactate is used continuously as a fuel by diverse cells under complete aerobic conditions (29). Currently it is known that, certain cancer cells may also actively use OXPHOS or a combination of OXPHOS and glycolysis for ATP production $(45,46)$. Interestingly, using high-resolution mass spectrometry, it was shown that ${ }^{13} \mathrm{C}$ lactate resides inside the mitochondria and can be used as a carbon source to synthesize lipids by cervical cancer and human lung cancer cells (47). Furthermore, it was revealed that LDHB is localized to the inner mitochondrial membrane and was associated with the regulation of the mitochondrial respiration using transmission electron microscopy (TEM) with gold-labeled lactate dehydrogenase B (LDHB) (47). Due to these results, it has been suggested that lactate is oxidized to pyruvate in the mitochondria by LDHB. However, it remains unknown how lactate enters inside the mitochondria in this cells, but it has been proposed that mitochondrial lactate import may be mediated by the monocarboxylate transporter (MCT) as in muscle and neuron cells $(48,49)$. Another study analyzing $\left[3-{ }^{13} \mathrm{C}\right]$-lactate metabolism in vitro and in vivo using nuclear magnetic resonance, indicated that lactate could be transported into and being oxidized by cancer cells (34, 50). Cancer cells are avid consumers of glucose, however, intratumoral levels of glucose are usually exceedingly low (51). Under these circumstances of low glucose, tumor cells uptake and oxidize lactate $(52,53)$. For instance, breast cancer derived-cells grown in different concentrations of glucose, produce high lactate levels, but switched from net lactate producer to consumers when glucose was limiting (54). Moreover by isotopomer analysis using ( $\mathrm{U}^{13} \mathrm{C}$ )-labeled lactate, it was determined that under conditions of glucose deprivation, over $50 \%$ of the total cellular pool of TCA cycle intermediates were derived from lactate (54). Whereas it was shown that lactate can serve as a fuel source when glucose is limited, a disagreement remains in the field as to whether it enters into the TCA cycle directly or if it must first be converted to glucose through gluconeogenesis (55). Further studies are required to decipher its role in cancer, to specifically elucidate what 
TABLE 1 | Lactate quantification in tumors and their association with metastatic spread.

\begin{tabular}{|c|c|c|c|c|}
\hline Cancer type & Sample & Lactate concentration & Method & References \\
\hline Head and neck cancer & $\begin{array}{l}\text { Cryobiopsies from head and neck } \\
\text { tumors, either with metastatic spread } \\
\text { or without }\end{array}$ & $\begin{array}{l}\text { With metastatic spread: } 12.3 \pm 3.3 \mu \mathrm{mol} / \mathrm{g} \\
\text { Without metastatic spread: } 4.7 \pm 1.5 \mu \mathrm{mol} / \mathrm{g}\end{array}$ & $\begin{array}{l}\text { Quantitative } \\
\text { bioluminescence imaging }\end{array}$ & $(32)$ \\
\hline Head and neck cancer & $\begin{array}{l}\text { Cryobiopsies from tumors from the } \\
\text { head and neck }\end{array}$ & $\begin{array}{l}\text { With metastatic spread: } 19.9 \mu \mathrm{mol} / \mathrm{g} \\
\text { Without metastatic spread: } 7.1 \mu \mathrm{mol} / \mathrm{g}\end{array}$ & $\begin{array}{l}\text { Quantitative } \\
\text { bioluminescence imaging }\end{array}$ & (31) \\
\hline Cervical cancer & Cryobiopsies at first diagnosis & $\begin{array}{l}\text { With metastatic spread: } 10.0 \pm 2.9 \mu \mathrm{mol} / \mathrm{g} \\
\text { Without metastatic spread: } 6.3 \pm 2.8 \mu \mathrm{mol} / \mathrm{g}\end{array}$ & $\begin{array}{l}\text { Quantitative } \\
\text { bioluminescence imaging }\end{array}$ & (30) \\
\hline Colorectal cancer & $\begin{array}{l}\text { Cryobiopsies from primary rectal } \\
\text { adenocarcinoma }\end{array}$ & $\begin{array}{l}\text { With metastatic spread: } 13.4 \pm 3.8 \mu \mathrm{mol} / \mathrm{g} \\
\text { Without metastatic spread: } 6.9 \mu \mathrm{mol} / \mathrm{g}\end{array}$ & $\begin{array}{l}\text { Quantitative imaging } \\
\text { bioluminescence }\end{array}$ & (33) \\
\hline Breast cancer & $\begin{array}{l}\text { Cryobiopsies from locally advanced } \\
\text { breast cancer }\end{array}$ & Median concentration range of $0.6-8.0 \mu \mathrm{mol} / \mathrm{g}$ & $\begin{array}{l}\text { Quantitative imaging } \\
\text { bioluminescence }\end{array}$ & (34) \\
\hline $\begin{array}{l}\text { Metastatic non-small cell lung } \\
\text { cancer }\end{array}$ & Venous and arterial blood sample & Median maximal levels was $1.8 \pm 2.2 \mathrm{mmol} / \mathrm{L}$ & Enzymatic method & (35) \\
\hline Human astrocytomas & Cyst content & $\begin{array}{l}\text { With metastatic spread: } 12.35 \mathrm{mmol} / \mathrm{L} \\
\text { Without metastatic spread: } 8.28 \mathrm{mmol} / \mathrm{L}\end{array}$ & Enzymatic method & (36) \\
\hline $\begin{array}{l}\text { Head and neck squamous } \\
\text { carcinoma }\end{array}$ & Xenograft in nude mice & $\begin{array}{l}\text { More radioresistant tumor ranged 7.3-25.9 } \\
\mu \mathrm{mol} / \mathrm{g}\end{array}$ & $\begin{array}{l}\text { Quantitative imaging } \\
\text { bioluminescence }\end{array}$ & $(37)$ \\
\hline $\begin{array}{l}\text { Head and neck squamous, } \\
\text { melanoma, rectum carcinoma } \\
\text { and adenocarcinoma }\end{array}$ & Xenograft in nude mice & $\begin{array}{l}\text { Median concentration in central areas: } 7 \\
\mu \mathrm{mol} / \mathrm{g} \\
\text { Median concentration in the periphery region: } \\
0.5 \mu \mathrm{mol} / \mathrm{g}\end{array}$ & $\begin{array}{l}\text { Quantitative imaging } \\
\text { bioluminescence }\end{array}$ & (38) \\
\hline
\end{tabular}

metabolic pathway is preferred and if it is dependent on the tumor metabolism.

Regarding the participation of lactate in the synthesis of TCA cycle intermediaries, Hui et al. (52) used three genetically modified mice cancer models, two for lung cancer and one for pancreas cancer, all under fasting conditions, showing that circulating lactate contributes to the generation of TCA cycle intermediaries. This contribution was higher than of glucose in the two lung cancer mouse models. Using intravenous infusions of ${ }^{13}$ C-labeled nutrients, Faubert et al. (56) showed that the circulatory turnover flux of lactate is the highest of all metabolites and exceeds that of glucose in human lung tumors. Recently, Bok et al. (57) showed that ${ }^{13} \mathrm{C}$-pyruvate is mainly directed to lactate production, associated with tumor progression and metastases.

Although it was shown that glutamine generates lactate in human glioma cells (41), it has been also shown that high amounts of lactate promotes glutamine uptake in $\mathrm{SiHa}$ and $\mathrm{HeLa}$ cells and consequently induces the glutaminolysis pathway. This increase in the intake and metabolism of glutamine was due to the stabilization of HIF $1-\alpha$ by lactate. HIF $1-\alpha$ then transactivates c-MYC proto-oncogene in a pathway that mimics a response to hypoxia. c-MYC is one of the main regulators of glutaminolysis and is also overexpressed in the vast majority of tumors (58). Lactate-induced c-MYC activation triggers the expression of the glutamine transporter ASCT2 and glutaminase 1 (GLS1), both resulting in improved glutamine uptake and catabolism (59).

These findings highlight the use of lactate in the generation of TCA cycle intermediaries and its role as a regulatory molecule of glutamine incorporation and metabolism, to finally serve as a source of energy in cancer cells. Also supports the importance of the mitochondrial function in cancer development.

\section{LACTATE SYNTHESIS: ROLE OF LDHA IN CANCER}

The inter-conversion between pyruvate and lactate is mediate by the nicotinamide adenine dinucleotide $\left(\mathrm{NAD}^{+}\right)$oxidoreductase $\mathrm{LDH}$ enzyme. This is a tetrameric enzyme composed of $\mathrm{M}$ and $\mathrm{H}$ protein subunits that are encoded by the LDHA and LDHB genes, respectively (60). The two subunits can then combine and form five homo or hetero tetramers in human tissues: LDH-1 $(4 \mathrm{H})$, LDH-2 (3H1M), LDH-3 (2H2M), LDH-4 (1H3M), and LDH-5 (4M). LDH5, also known as LDHA, is the predominant isoform found in skeletal muscle. In contrast, LDH1 also known as LDHB, is the predominant isoform found in heart muscle (61). LDHA preferentially reduces pyruvate to lactate, while LDHB supports conversion of lactate to pyruvate in cells that utilize lactate as a nutrient source for oxidative metabolism or gluconeogenesis (62). Pyruvate is reduced to produce lactate while NADH is oxidized to $\mathrm{NAD}^{+}$in a thermodynamically favored reaction. In the opposite direction, lactate is oxidized to form pyruvate, while $\mathrm{NAD}^{+}$is reduced to NADH (63).

\section{LDHA Expression in Tumors}

Several reports indicate that LDHA expression and its activity is increased in numerous types of tumors and is associated with lower event-free survival rate and with resistance to chemotherapy treatment. For instance, high LDHA levels in serum could be a negative prognostic biomarker in osteosarcoma, pancreatic cancer, and lung adenocarcinoma (64-67). On the other hand, knocking down the expression of LDHA in lung adenocarcinoma cells inhibits the proliferation, invasion, migration and colony formation (67). In human lymphoma 
and pancreatic cancer, knocking down the expression of LDHA by siRNA reduces ATP levels and induces significant oxidative stress and cell death in human lymphoma and pancreatic cancer xenografts in mice (68).

The ability to monitor when a disease arises, how it progresses and to evaluate the result of treatment through non-invasive techniques is the most desirable goal in clinical setting. Noninvasive sampling is the most useful and valuable alternative because no stress is generated in the oncological patient. LDHA determination in saliva sample has been proposed for detection and monitoring of oral squamous cell carcinoma (OSCC), since the major source of salivary LDHA are the oral epithelium-shedding cells. Any pathological changes in the oral epithelium should be reflected diagnostically in the saliva, and the aggressiveness of different histological grades of OSCC could be assessed (69). Thus, the LDHA levels could be an excellent diagnostic marker. In this regard, a positive correlation between the LDHA expression and the histopathological grading was found in saliva samples from patients with OSCC (70). The expression of salivary LDHA in patients with OSCC was significantly higher than that of healthy individuals. Importantly, the levels of salivary LDHA in patients with squamous cell carcinoma of the tongue and lower oral cavity were significantly higher than other patients affected with squamous cell carcinoma in other parts of the head and neck (71).

\section{Phosphorylation of LDHA and Its Role in Cancer}

It was demonstrated that LDHA is phosphorylated at two specific tyrosine sites, tyrosine 10 (Y10), and tyrosine 83 (Y83). Phosphorylation in Y10 increases LDHA activity by enhancing the active tetrameric LDHA conformation, which induces the binding of NADH and promotes Warburg effect in human head and neck squamous cell carcinoma (HNSCC), lung cancer, breast cancer and prostate cancer cells (72). Interestingly, it was demonstrated that high levels of phosphorylated LDHA in human prostate cancer tissues were associated with short recurrence and poor survival times in patients (73). The tyrosine kinases involved in the Y10 phosphorylation of LDHA are HER2, the avian sarcoma viral oncogene v-src homolog ( $\mathrm{Src})$ and the Fibroblast growth factor receptor 1 (FGFR1), this phosphorylation promotes the Warburg effect and pro-invasive and pro-metastatic potential of cancer cells $(73,74)$. Recently, it was identified that cyclin G2 could directly interact with LDHA and negatively regulate the phosphorylation of Y10 in LDHA, although the mechanism by which cyclin G2 reduce the Y10 phosphorylation remains unknown, this interaction inhibits the Warburg effect and tumor progression in glioma (75). Taken together the phosphorylated-induced activation of LDHA provides other mechanism used by tumor cells in order to establish a malignant phenotype. However, there are very few studies on this topic, so it is important to investigate whether post-translational modifications such as phosphorylation in metabolic enzymes such as LDHA are part of the broad mechanism by which tumorigenesis is promoted by associating signaling and metabolism pathways.

\section{NON-CANONICAL FUNCTIONS OF LDH IN CANCER}

Metabolic enzymes exhibit "promiscuous" catalytic activities (76). In addition to the above-described canonical functions of $\mathrm{LDH}$, it has recently been demonstrated that LDHA exhibits noncanonical roles, which are also involved in tumor progression.

Based on this, Intlekonfer et al. (77) observed that LDHA produces the oncometabolite L-2-hydroxyglutarate (L-2HG) under hypoxic conditions in glioblastoma, via alternative substrate usage and additional contributions from malate dehydrogenase 1 and 2 (MDH 1/2). The authors also demonstrated that during hypoxia, the resulting increase in L-2HG is necessary and sufficient for the induction of increased methylation of histone repressive marks such as histone 3 lysine 9 (H3K9me3). Later, the same research group also demonstrated that the L-2HG produced by LDHA is favored in an acidic environment and promotes the HIF 1- $\alpha$ stabilization under normoxia conditions (78). HIF $1-\alpha$ is associated with metabolic regulation, specifically with tumor lactagenesis, because of the induction of the expression of LDHA, MCT4 and the membranebound carbonic anhydrase IX (CAIX), and in this way regulates the tumor acid environment and tumor progression $(79,80)$. Recently, it has been reported that LDHA translocates to the nucleus, induced by reactive oxygen species (ROS) in cervical cancer. Once in the nucleus, LDHA in its dimeric form produces the antioxidant metabolite $\alpha$-hydroxybutyrate $(\alpha-\mathrm{HB}) . \alpha-\mathrm{HB}$ induces $\mathrm{H} 3 \mathrm{~K} 79$ hypermethylation through the interaction between methyl-transferase DOT1L and LDHA, demonstrating that LDHA nuclear translocation appears to be essential for maintaining redox balance and sustaining cell proliferation through epigenetic regulation (81).

This promiscuous enzymatic activity of LDHA might represent a metabolic response to multiple environmental stimuli including hypoxia and acidosis, conditions frequently found in tumor microenvironment of aggressive tumors. Future investigations will be directed at elucidating the role as well as how deregulation L-2HG and $\alpha$-HB by LDHA might contribute to oncogenesis.

\section{LACTATE TRANSPORT: ROLE OF MCTS IN CANCER}

Eukaryotic cells require the efflux of lactate and $\mathrm{H}^{+}$to the extracellular space to prevent intracellular acidification and sustain continuously high rates of glycolysis, since the accumulation of cytosolic lactate reduces the glycolytic rate via inhibition of the rate-limiting enzyme fosfofructokinase-1 (PFK1) (82). Lactate itself cannot cross the plasma membrane by free diffusion. Hence, it requires a specific transport mechanism provided by proton-like MCTs $(83,84)$ It was identified that lactate shuttle is driven by a concentration and $\mathrm{pH}$ gradient or by the cellular redox state in rat skeletal muscle (28).

MCTs belong to the family of solute carrier (SLC) transporters, composed by 52 families of the membrane transport proteins; in particular, the SLC16 family encodes 14 MCTs isoforms and 
plays a significant role in the absorption, tissue distribution and clearance of both, endogenous and exogenous compounds (83). MCTs 1-4 are known lactate transporters, but they can carry other monocarboxylates such as pyruvate and the ketone bodies such as acetoacetate, $\beta$-hydroxybutyrate and acetate (85). Two proteins, basigin (CD147) and embigin (gp70), have been identified as important chaperone proteins implicated in the trafficking of the MCTs $1-4$ to the plasma membrane (86-88). Recently, it was discovered that the TMPRSS11B protease also regulates the function of MCT4 mediated by CD147 in cancer cells (89).

Over-expression of lactate transporters is a common feature of some cancers with high metabolic rate (90). For instance, high expression of MCT1, MCT4 and its chaperone CD147 is associated with decreased progression-free survival in clear cell renal cell carcinoma, head and neck cancers and neuroblastoma (91-93). In human bladder cancer, high MCT1 expression was associated to shorter overall survival than those with lowMCT1 expression, and the knockdown of MCT1 inhibits cell proliferation, migration and invasion in a cellular model (94). In cervical cancer, it has been shown that CD147 expression was higher in squamous and adenocarcinoma tissue than in their non-neoplastic counterparts, and both MCT1 and MCT4 were more frequently expressed in CD147 positive cases $(90,95)$. This over-expression of MCT1 and 4 was associated with lymph node and distant metastases in melanoma and adenocarcinoma $(96,97)$. Interestingly, disruption of MCT1 or MCT4 in renal cell carcinoma, pancreatic cancer, breast cancer and prostate cancer has been shown to exert significant antitumor effects both in vivo and in vitro with increased accumulation of intracellular lactate $(98,99)$. In $\mathrm{MCT}^{-} /^{-}$and wild type mice with oral cancer, it was observed that mouse tongues from $\mathrm{MCT}^{-} /^{-}$mice developed significantly fewer and less extended invasive lesions than wild type mice indicating an important role for MCT4 in tumor metastasis (100). Additionally, MCT4 was detected in foci of the basal layer undergoing transformation, in areas of carcinoma in situ, and also in invasive carcinomas (100). These findings support the important role of MCTs in tumor metastasis development.

\section{LACTATE IN TUMOR MICROENVIRONMENT: TUMOR-ASSOCIATED ACIDITY}

Lactate is largely produced within the TME and is used as an energy-rich substrate, signaling molecule and as an important immune suppressor by tumors (101). TME consist of malignant cancer cells, endothelial cells, cancer associated fibroblasts (CAFs), immune cells and non-cancer cell stroma conformed by numerous peptide factors (growth factors, chemokines, cytokines and antibodies) (20). The glycolytic cancer cells and CAFs are the main producers of lactate, simply because they are the most abundant populations within the neoplasm (101). TME enforce to metabolic adaptability, physical pressure, oxidative stress, nutrient deprivation and competition, immune surveillance as well as adaptability to hypoxic and acidic environment having an enormous impact on tumor malignancy (102). In agreement with this, it was demonstrated that $\mathrm{pH}$ 6-6.5 in tumor microenvironment is associated with metastasis, angiogenesis and therapy resistance, a characteristic phenotype of more aggressive tumors $(103,104)$. This tumor acidification is a consequence of high lactate production in a poorly perfused environment, as well as a high activity of the CAIX (105). CAIX is a transmembrane protein belonging to the $\alpha$ carbonic anhydrase family of zinc metalloenzymes that catalyze the reversible hydration of carbon dioxide to bicarbonate ions and $\mathrm{H}^{+}$(106) that is overexpressed in tumors and is associated with unfavorable responses to first-line therapy (107). The tumor hypoxia induces the expression of the CA9 gene in a HIF 1- $\alpha$ dependent manner; on the other hand it was shown that lactate promotes normoxic expression of CA9 genes through HIF 1- $\alpha$ stabilization independently of hypoxia (108). CAIX acts as an extracellular $\mathrm{pH}$-stat, maintaining an acidic tumor extracellular $\mathrm{pH}$ favoring invasion and metastasis (105).

By cooperating with anion exchanger 2 (AE2) and $\mathrm{Na}^{+} /$bicarbonate co-transporter 1 (NBCe1), CAIX serves as a $\mathrm{pH}$ regulatory component that provides acid-base balance. Interestingly, it was shown that CAIX work in support with diverse acid extruders such as MCT1 and MCT4 (109, 110), and as mentioned earlier, MCT-mediated $\mathrm{H}^{+}$efflux exacerbates extracellular acidification and supports the formation of a hostile environment where cancer cells, that have adapted to these conditions, can outcompete normal cells, which further enhances tumor progression.

The proteoglycan like (PG) domain of CAIX could function as a "proton antenna" to facilitate MCT1 and MCT4 transport activity in hypoxic cancer cells (111). Recently, it was found that CAIV also facilitate the activity of MCT1, MCT2, and MCT4 via a non-catalytic mechanism and requires direct biding between CAIV in the amino acid residue His- 88 and a charged amino acid in the extracellular domain of the chaperones CD147 and GP70 (112).

\section{LACTATE EXCHANGE BETWEEN CANCER CELLS: METABOLIC SYMBIOSIS}

As previously described, the lactate shuttle theory occurs in normal physiology (29). Interestingly, this mechanism is also observed in cancer cells where it is known as "metabolic symbiosis." Sonveaux et al. (53) found that cervical cancerderived SiHa cells, which expressed higher levels of MCT1 but lower levels of MCT4, consumed significantly more lactate and less glucose than colorectal cancer WiDr cells, conversely, WiDr cells, which expressed higher levels of MCT4 and lower levels of MCT1, consumed less lactate and more glucose than SiHa cells. Consistent with the proposed "tumor metabolic symbiosis," metabolically heterogeneous regions within and between tumors were identified, which are regulated by TME conditions such as hypoxia in the center of the tumor and better oxygenated regions in the periphery (113) (Figure 2). Furthermore, it was shown that a high lactate uptake occur only in aerobic tumor regions in breast cancer (34). The oxygenated cancer cells, close 


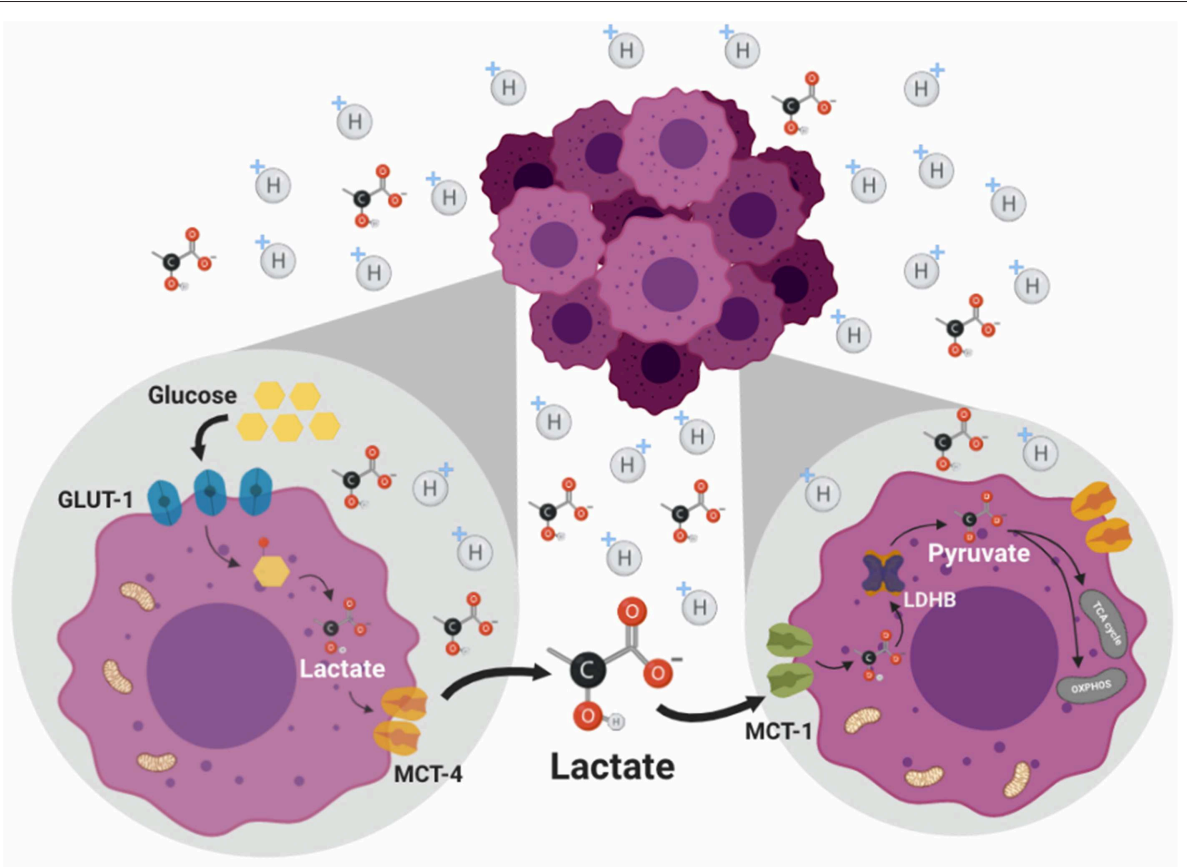

\section{Glycolytic tumor cell}

\section{Oxidative tumor cell}

FIGURE 2 | Metabolic symbiosis. Solid tumors are characterized by metabolic heterogeneity. Glycolytic tumor cancers are sustained by a favorable location with high nutritional availability. This phenotype is regulated by a differential expression of MCTs, where glycolytic cells preferentially express MCT4 favoring lactate export. Meanwhile, oxidative cells express MCT1 transporter which preferentially promotes lactate import. Then, lactate is used by these cells as an energetic source due to its conversion to pyruvate which enters the TCA cycle in the mitochondria. The presence of lactate allows a metabolic symbiosis between hypoxic cancer cells (glycolytic) and with normoxic cancer cells (oxidative).

to blood vessels, are sustained by a favorable location with high nutritional availability and can establish a metabolic symbiosis with hypoxic cancer cells, essential for the progression of a fastgrowing tumor characterized by hypoxic regions. This tumor metabolic symbiosis is supported by differences in MCT1 and MTC4 expression and activity. MCT1 (SLC16A1) is ubiquitously expressed and has a high affinity for lactate $(3-6 \mathrm{mM})$; this transporter is the main lactate exporter where intracellular lactate levels are low (84). On the other hand, MCT4 (SLC16A3) is expressed strongly in glycolytic tissue (114) and has low affinity for lactate $(25-30 \mathrm{mM})$ and it does not import serum lactate $(<2 \mathrm{mM})$ (115). In tumors, it was demonstrated that both, the glucose transporter 1 (GLUT1) and MCT4 were induced in distal hypoxic cells in a HIF 1 - $\alpha$-dependent fashion (116). Instead, tumor cells proximal to blood vessels, expressed the lactate transporter MCT1. These differences in the regulation of the expression and activity of lactate transporters underpin the metabolic symbiotic model.

Despite the avidity by which tumor cells uptake glucose, glutamine or lactate in vivo, encounter conditions of nutrient scarcity are often an issue as a result of the increased rate of nutrients consumption and the inadequacies of the tumor vascular supply, for this reason tumors have develop various nutrient scavenging strategies to bypass these limitations, for instance lactate exchange (117).

\section{LACTATE EXCHANGE BETWEEN CANCER CELLS AND CAFS: REVERSE WARBURG EFFECT}

Another way by which it is believed that cancer cells survive under nutrient scarcity is by a cross talk between stroma cells from tumor microenvironment and tumoral cells, process known as "reverse Warburg effect," in which aerobic glycolysis takes place in CAFs, rather than in epithelial cancer cells, fueling cancer cells via metabolite transfer, particularly lactate (118) (Figure 3). CAFs constitute the more abundant cell population in tumors and have been associated with tumor progression, invasion and metastasis directly through paracrine pathways (119). Fibroblasts possess a metabolic phenotype characterized by increased glycolysis and decreased OXPHOS. During tumor initiation, neoplastic cells recruit CAFs to the surrounding area through the ROS production inducing oxidative stress. As a consequence, CAFs suffer DNA damage, initiating several catabolic pathways, such as autophagy and more specifically mitophagy (120). Autophagy is a catabolic process of macromolecules (proteins, lipids) and organelles whereby intracellular components are enveloped in double-membrane vesicles, known as autophagosomes, which ultimately fuse with lysosomes where the content is degraded and recycled into the cytosol (121). On the other hand, mitophagy is a specific 


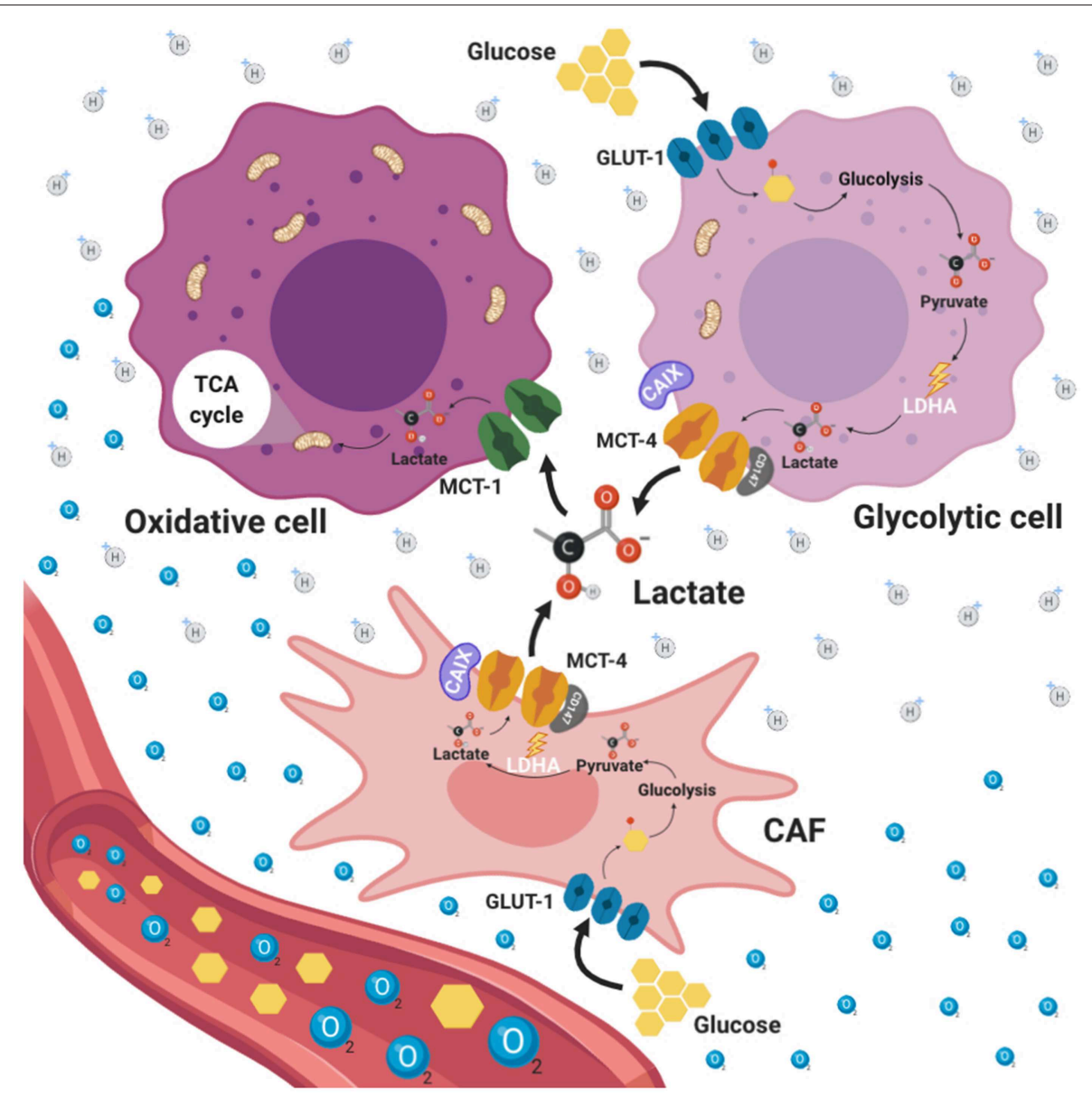

FIGURE 3 | Reverse Warburg effect. Tumor microenvironment (TME) is an ultrastructure consisting of different cell types including tumor cells, stromal cells, immune cells, blood vessels and cellular metabolites such as lactate. TME promotes different processes aimed to enforce metabolic adaptability, oxidative stress, nutrient competition, immune surveillance. This adaptability to hypoxic and acidic environments stimulates tumor malignancy. Tumor cells and cancer associated fibroblasts (CAFs) with a glycolytic phenotype represent the principal source of lactate production within TME which is favored by the presence of GLUT1. Additionally, CAFs exhibit high expression of MCT4 dedicated to lactate export. In this way, CAFs can interchange lactate with oxidative tumor cells which use lactate as a fuel through the TCA cycle. This phenomenon is known as reverse Warburg effect.

process performed in CAFs used for the removal of mitochondria through autophagy. CAFs with dysfunctional mitochondria shift their metabolism toward glycolysis, producing energyrich molecules, such as lactate, which is exported to the tumor microenvironment and consequently can be used by neighboring cancer cells via oxidative mitochondrial metabolism providing an alternative energy source promoting tumor initiation, progression and metastasis (122). Interestingly, it has been shown that CAFs are able to stimulate cancer cell proliferation and progression through multiple mechanisms. For instance, in a lung cancer model, CAFs underwent increased aerobic glycolysis and promoted the epithelial mesenchymal transition, migration and invasion of non-small-cell lung carcinoma (NSCLC) cells, in contrast, NSCLC cells experienced enhanced oxidative phosphorylation upon CAF stimulation, with an increase in ATP generation, thereby an activation of the PIK3/Akt and MAPK/ERK pathways occurred (123). Furthermore, colorectal cancer cells induce oxidative stress in microenvironment fibroblast, which then undergo metabolic changes, including increased expression of glycolytic enzymes, reduced TCA cycle enzymes and autophagy proteins such as microtubule-associated protein 1A/1B-light chain 3 (LC3), Bcl2 interacting protein 3(BNIP3), and p62 (124). In this model, the increased autophagy promoted survival of cancer cells by providing nutrients for cell proliferation and protection against oxidative damage. Moreover, hypoxia-induced oxidized ATM promoted the glycolytic activity of CAFs by phosphorylating GLUT1 at S490 and in consequence induced its membrane translocation (125). In addition, the PKM2 expression in CAFs was up regulated by the activation of ATM through PI3K/Akt signaling pathway.

Another study showed that intercellular contact activated stromal fibroblasts, triggering the expression of GLUT1, lactate production, and extrusion of lactate by the de novo expressed MCT4 (126). Conversely, prostate cancer cells, upon contact with CAFs, were reprogrammed toward aerobic metabolism, with a 
decrease in GLUT1 expression and an increase in lactate upload via MCT1. Metabolic reprogramming of both stromal and cancer cells was under strict control of the HIF 1- $\alpha$, which drove redoxand SIRT3-dependent stabilization of HIF $1-\alpha$ in normoxic conditions. Prostate cancer cells gradually became independent of glucose consumption, while developing a dependence on lactate driving anabolic pathways and thereby cell growth (126). Lactate shuttle between CAFs (released by MCT4) and tumor cells (absorbed via MCT1) may accelerate tumor cell invasion by activation of TGF- $\beta 1 / \mathrm{p} 38$ MAPK/MMP2/9 signaling (125).

This reverse Warburg effect provides tumoral metabolic plasticity that enables tumor cells to adapt to variations in microenvironment and represents a change to the paradigm on the metabolism of neoplastic cells, indicating that not all tumors depend on glycolysis (Warburg effect), since some tumors exhibit high dependence of OXPHOS and consequently of mitochondrial function (127). It has been observed that mitochondrial metabolism is important for cancer development. Interestingly, frozen sections of human breast tumors exhibit have a high expression and activity of cytochrome $\mathrm{C}$ oxidase (COX), NADH and succinate dehydrogenase in comparison to normal cells (122). This effect was related to greater aggressiveness of the tumors. Moreover, it was shown that the mitochondrial complex I NADH dehydrogenase activity is a critical player in the aggressive phenotype in breast cancer through the regulation of $\mathrm{NAD}^{+} / \mathrm{NADH}$ redox balance, mTORC1 activity and autophagy (46). The mitochondrial function and its relation with cancer development is a very interesting topic excellently discussed in the review of Vyas et al. (5).

\section{LACTATE AS A KEY MOLECULE IN REGULATION OF THE IMMUNE RESPONSE IN CANCER}

The immune system is responsible for protecting the body from damage caused either by pathogens or by tumor cells through the detection and elimination of aberrant cells (128). The presence of neoplastic cells causes the activation of both, the innate and adaptive immune responses in order to maintain homeostasis (129). Nevertheless, tumor cells have developed different mechanisms to evade the immune system including a constant remodeling at the genetic, epigenetic and metabolic levels, in order to resist apoptosis and select tumor variant cells resistant to immune recognition. In addition, TME favors the induction and recruitment of different immune cells and molecules constituting an immunosuppressive environment, favoring the development of the tumor mass (130). It has been shown that metabolic alterations play an important role in cancer development, progression and maintenance (131). As part of the high metabolic rate and reprograming, tumor cells secrete metabolic products as lactate, which is thought to act as an important oncometabolite in the metabolic reprogramming of cancer. In turn, the high levels of secreted lactate promote acidosis in the tumoral environment favoring processes such as metastasis, angiogenesis and importantly, immunosuppression, which has been associated to a worse clinical prognosis (132).

Different cells are involved in the recognition and elimination of tumor cells including natural killer (NK), natural killer $\mathrm{T}$ (NKT) cells, macrophages, dendritic cells (DC), macrophages, and lymphocytes (129).

NK cells induce the destruction of stressed cells, cells infected by viruses or bacteria as well as tumor cells (133); this last action performed through their "killer" receptor (KIR) (134). The major histocompatibility class I (MHC-I) complex is recognized by KIR receptors inhibiting the activation of NK cells, however, tumor cells display diminished amounts of MHC-I which in consequence triggers the activation of NK cells, with the subsequent release of their cytoplasmic granules containing granzyme and perforin finally inducing cell lysis (135). Nevertheless, tumor cells inhibit the activation of NK cells triggered by lacking of $\mathrm{MCH}$ class I expression through the release of soluble molecules such as MHC class I chainrelated protein A (MICA) and MHC class I chain-related protein $\mathrm{B}$ (MICB), which bind to the activator receptor (NKG2D) on NK cells surface causing the endocytosis and its subsequent degradation, leading to the inactivation of NK cells (136). In addition to this mechanism for inhibiting NK cells action, it has been demonstrated that the presence of lactate induces the apoptosis of NK cell, since lactate decreases the intracellular $\mathrm{pH}$ resulting in mitochondrial dysfunction in colon cancerderived cells (137). It was also observed that those NK cells that migrate to the tumor cannot regulate intracellular $\mathrm{pH}$, causing mitochondrial stress and subsequent apoptosis.

Using a pancreatic cancer-derived mouse xenografted model, the silencing of $\mathrm{LDH}$ caused a reduction of the tumor associated to a better cytolytic activity of NK cells (138). Thus, tumor microenvironment easily affects immune actions by producing lactate, favoring the development of cancer.

NKT are another immune cells with antitumor activity, which recognize glycolipids through the CD1d receptor on the tumor cells, this interaction activate its antitumor action releasing the content of their cytoplasmic granules (perforin and granzyme B) as well as cytokines favoring activation of both, innate and adaptative immune response (139). It has been shown that lactate present in TME, blocks IFN $\gamma$, and IL-4 production from NKT cells, since lactate inhibits mTOR signaling due to the inhibition of the nuclear translocation of promyelocytic leukemia zincfinger (PLZF) avoiding the activation of NKT cells (140). These results are in agreement with those reported recently by Kumar et al. (141), showing that high lactate environment is detrimental for NKT cell survival and proliferation. This indicates that the production of lactate by the tumor microenvironment inhibits the anti-tumor action of NK and NKT cells, promoting tumor development (Figure 4).

DCs are antigen-presenting cells, which play a major role in the innate and adaptive immune responses (142). DCs main function relies on its ability to detect and phagocytize pathogens, but also on the recognition of tumor cells, by processing and presenting antigens that finally activates virgin $\mathrm{T}$ lymphocytes (143). DCs present the antigen through the MHC-II activating $\mathrm{CD}^{+} \mathrm{T}$ (LT) or helper cells, that depending on the produced 


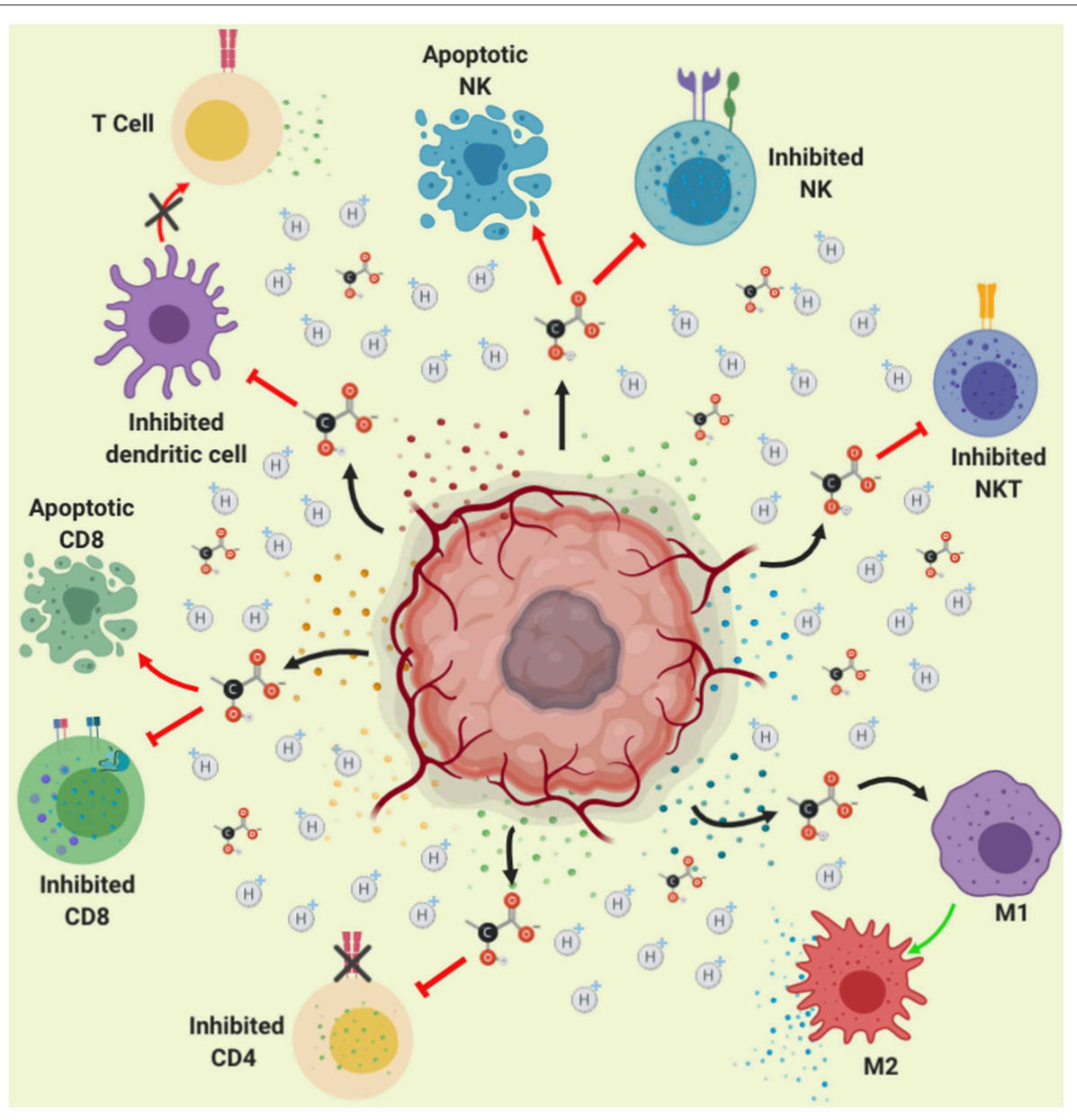

FIGURE 4 | Role of lactate in immune suppression. Lactate secretion by tumor cells promotes acidification of the tumor microenvironment (represented in yellow color). This acidification of the medium, reduces the $\mathrm{pH}$ within the immune cells affecting signaling pathways finally causing inhibition of the activation and proliferation of CD4, CD8, NK, NKT, and dendritic cells. Moreover, lactate-induced acidification causes apoptosis in CD8 lymphocytes and NK cells, thus lactate contributes to immune evasion. Furthermore, the acidification of the medium causes the polarization of the macrophages toward the M2 subpopulation, which favors growth, invasion and migration of the tumor.

cytokine environment, these will differentiate into a variety of subpopulations of helper T cells mainly Th1, due to the action of IL-12 and IFN- $\gamma$ produced by NK, NKT and macrophage cells $(144,145)$. In addition, DCs present antigens to cytotoxic $\mathrm{T}$ lymphocytes (CTL) or CD8, these cells recognize tumor antigen through MHC-I producing the elimination of tumors (146). After the recognition of non-own peptides (such as tumor antigens) through MHC-I, CD8 T cells will be activated causing cytokine release, mainly TNF- $\alpha$ and IFN- $\gamma$ (147), as well as their cytoplasmic granule (perforin and granzime B) content toward neoplastic cells, it also induces apoptosis through the interaction of dead molecules such as Fas with Fas Ligand present in the tumor cells, causing lysis and apoptosis of the tumor cells (148). The T lymphocytes (CD4 and CD8) play an important role in eliminating tumor cells; this process is known as immunesurveillance (149). The lack of response of the lymphocytes could also be due to the fact that it has been shown that lactate affects the dendritic cells, prevents their differentiation and makes them tolerogenic, leading to an increase in the production of IL-10, a potent immuno-suppressive cytokine (150).

IL-10 is an anti-inflammatory cytokine with potent immunesuppressive action, since it inhibits the production of proinflammatory cytokines such as IFN $\gamma, \mathrm{TNF} \alpha$, IL- $1 \beta$, and IL-6; moreover, IL-10 prevents DC maturation in part by inhibiting the expression of IL-12, necessary for Activating of type 1 helper $\mathrm{T}$ cells and stimulates the production of cytotoxic $\mathrm{T}$ cells and $\mathrm{NK}$ cells. It also stimulates the production of interferon $(151,152)$. Also, IL-10 inhibits Th1 differentiation and production of IL-12 (153). In addition, IL-10 inhibits the expression of $\mathrm{MCH}-\mathrm{I}$ and different co-stimulatory molecules inhibiting $\mathrm{T}$ cell activation $(154,155)$. Several reports indicate an IL-10 increase in serum levels in patients with different types of cancer such as hepatocellular, head and neck, lymphoma, leukemia and melanoma (155). Therefore, over regulation of IL-10 production by tumor cells promotes tumor progression through the escape of immunosurveillance performed by NK, 
CD4, and CD8 lymphocytes. In addition, lactate produced by the tumor cell promotes the overexpression of IL-23, present in different types of tumors (colon, breast, stomach, melanoma) (156), the presence of this cytokine promotes expression of IL17, Matrix metalloprotease 9 (MMP-9), increases angiogenesis and reduces the infiltration of CD8 in the tumor, promoting immunosuppression and tumor growth (157). Thus, increased IL-10 favors tumor microenvironment.

A study quantified lactate levels in the serum of patients with different malignancies (lymphoid malignancies, myeloid malignancies, breast cancer, gastrointestinal cancer, urogenital cancer, sarcoma, lung cancer, melanoma and other types of cancer), finding high levels of lactate, furthermore, the authors demonstrated that lactate inhibits T-cell proliferation and alters the cytokine production of CTLs in cultured CTLs (158), therefore, lactate promotes immunosuppression and the development of cancer through the inhibition of $\mathrm{T}$ lymphocytes.

Lactate produced by tumor microenvironment participates in immune escape through an inhibition of lymphocytes activity. As demonstrated in samples of melanoma patients showing that high LDHA expression is associated not only with poor prognosis, reduced disease-free survival, but also with lower expression of $\mathrm{T}$ cell markers (159). Moreover, in a melanoma mouse model it was found that tumor-derived lactate reduced the numbers and activity of CD8 ${ }^{+} \mathrm{T}$ cells as well as NK cells, both in vitro and in vivo. This because lactate concentrations above $20 \mathrm{mM}$ caused the apoptosis of T and NK cells, which may explain smaller proportions of T cells and NK cells in tumors with higher concentrations of lactate (159). Similar results were observed recently by Daneshmandi et al. (160), where blocking of LDHA in melanoma tumors effectively enhances infiltration of $\mathrm{CD}^{+} \mathrm{T}$ cells and NK cells in the tumor microenvironment. Interestingly, they also demonstrated that blocking LDHA in tumor cells improves the efficacy of anti-programmed cell death-1 (PD1) therapy in melanoma (160). Therefore, this is a mechanism used by tumor cells to evade the action of $\mathrm{T}$ lymphocytes. Moreover, the acidic $\mathrm{pH}$ (6.5) suppress T-cell functions including IL-2 secretion and the activation of T-cell receptors and the treatment with proton pump inhibitor (esomeprazole) delayed cancer progression in tumor bearing mice (161). Recently, it was shown that the acidic $\mathrm{pH}$ environment (6.6) blockades the T-cell activation and decreases IFN $\gamma$ secretion (162).

There is great evidence indicating that lactate promotes immunosuppression thus preventing the recognition of tumor cells and favoring carcinogenesis. Interestingly, lactate has a different effect on macrophages, as demonstrated by Colegio et al. (163) tumor-cell-derived lactate has an important impact in the macrophages polarization and the promotion of tumor growth. This is because lactate induces mainly vascular endothelial growth factor (VEGF) and arginase 1 (Arg1) expression via HIF $1-\alpha$, favoring the TAM polarization. Moreover, the upregulation of VEGF and Arg1 in macrophages contributes to the development of cancer since tumor growth is supported by inducing neovascularization and by providing the substrates for cancer cell proliferation. Otherwise, it has been demonstrated that lactate activate human macrophages to a M2 phenotype and stimulate the secretion of Chemokine (C-C motif) ligand
5 (CCL5) by activation of Notch signaling in macrophages. The authors also found that CCL5 increased cell migration and induced cancer cell epithelial to mesenchymal transition in a breast cancer cell model (164). Additionally, it was shown that lactate activates the ERK/STAT3 signaling inducing the M2 macrophage polarization favoring proliferation, migration, and angiogenesis in a breast cancer model (165).

\section{LACTATE IN TUMOR METASTASIS AND THERAPY RESISTANCE}

Metastatic dissemination represents a malignant character of cancer with important clinical consequences since the majority of cancer-associated deaths are caused by metastatic disease rather that the primary tumors (166). Intratumor lactate levels can be used as a prognostic factor and a therapy response biomarker. It has been shown that high concentrations of lactate in biopsies of cervical, lung, head and neck, colorectal and breast cancers are associated with an increased risk for developing metastasis, and such levels of lactate indicate a bad prognosis for survival in cancer patients $(30,31,35,167)$ (Table 1). In human astrocytomas, a positive correlation between the grade of lesion and high lactate concentration was found using stereotactic brain biopsy specimens (36). Moreover, using imaging bioluminescence from primary cryo-tumor sections of human cancers, lactate concentrations were significantly higher in cervical tumors with metastatic spread (30). Another study encompassing 34 biopsies from patients with cancers of the head and neck, it was demonstrated that elevated tumor lactate concentrations are associated with the subsequent development of nodal or distant metastases (31).

The measurement of intratumor lactate levels using noninvasive methodologies; such as nuclear magnetic resonance (MRS) is currently used (168). In HER2-positive breast cancer lactate can be used as a quantitative and non-invasive biomarker of sensitivity to trastuzumab. Using MRS in a cohort of 39 frozen HER2-positive breast cancer specimens of patients who showed response to trastuzumab, a positive correlation between the transcript levels of HER2 and increased intratumor lactate concentration was found, moreover in vitro analyses using HER2-high expression (ZR75.30, SKBR3, BT474, and HCC1954) or HER2-low expression (MDAMB361 and MDAMB453) cell lines, it was found a direct correlation between HER2 transcript levels and lactate content in milieu (169).

Resistance to therapy is frequently developed during the clinical application of antineoplastic agents and is a major obstacle in the treatment of malignant cases (170). A substantial percentage of cancer patients exposed to an antineoplastic agent either does not benefit from the treatment (primary resistance) and shown reduced responsiveness or undergo tumor relapse progression (secondary resistance) (171). This resistance may be due to both, cell-autonomous and non-cellautonomous mechanisms, TME is important in the initiation and maintenance of non-cell-autonomous drug resistance through various mechanisms including hypoxia, extracellular acidity and production of soluble factors such as lactate (172) (Figure 1). The 
role of lactate in resistance to therapy has been demonstrated using in vivo and in vitro models. High lactate concentration in xenografted Nude mice with five human HNCSCC cell lines treated with irradiation (4Gy) within 6 weeks correlates with radio resistance (37). In NSCLC, it has been shown that lactate is a key molecule involved in resistance to therapy based on tyrosine kinase inhibitors (TKIs), specifically with c-MET receptor tyrosine kinase inhibitor JNJ-605 and the epidermal growth factor receptor (EGFR) inhibitor erlotinib (173). In this work, the authors demonstrated that prolonged treatment with these TKIs induced lactate production by tumor cells, which in turn instructed the TME cells to produce hepatocyte growth factor (HGF), enforcing drug resistance and tumor progression. Targeting tumor lactate metabolism was sufficient to overcome resistance, demonstrating the causative role of lactate in resistance to therapy. Another study tested several metabolic inhibitors including BEZ235, GDC0980 (dual PI3K/mTOR inhibitors), or LY294002 and GDC0942 (PI3K inhibitors) showing an inhibition of cell proliferation of breast cancer cells in high glucose media (54). Nevertheless, when lactate was used as the primary metabolic substrate these cells were completely resistant to these inhibitors, suggesting that cancer cells bypass the need for glycolysis by utilizing lactate and are thus less sensitive to PI3K/mTOR inhibitors.

Due to the role of lactate in tumor initiation and metastatic dissemination previously mentioned, impairing lactate homeostasis is a promising approach for cancer therapeutics and has been implemented in several preclinical and clinical trials, it is also essential to establish a synergy between lactate inhibitors and other adjuvant therapies.

\section{THERAPEUTIC APPROACHES IN LACTATE METABOLISM}

\section{Targeting Lactate Production}

Glycolytic tumors undergo a metabolic reprogramming transforming themselves into a highly glycolytic and poorly oxidative phenotype with lactate formation as the end product despite normoxic conditions. This high glycolytic metabolism supplies precursors for biomolecules in cellular structure and processes allowing cell survival and proliferation (174, 175). In agreement with the above mentioned with regard to essential role of lactate in tumor development, metastasis and its role in drug resistance, impairing the lactate biogenesis could be a promising approach to cancer therapeutics (Table 2).

Several methods have focused in targeting lactate production, for instance Le et al. (68) demonstrated an increase in oxygen consumption, ROS production and late cell death even necrosis, in P493 cells (B-lymphoid cells) after inhibiting the expression of LDHA using siRNAs as well as employing a Gossypol analog as FX11, a direct competitive inhibitor of LDHA. Another compound FK866, that hinders the $\mathrm{NAD}^{+}$synthesis through direct inhibition of Nicotinamide Phosphoribosyl transferase (NAMPT) was used. The use of both molecules was toxic for P493 cells either alone or in combination, causing a reduction of mitochondrial membrane potential resulting in profound inhibition of cell proliferation. Tumor xenograft models using P493 (lymphoma) and P198 (pancreatic) cells were performed in order to demonstrate the potential of both compounds in the inhibition of tumorigenesis in vivo. FX11 effectively inhibited tumor growth in xenografts derived from both cell lines; the combination of FX11 with FK866 induced tumor regression in the human lymphoma xenograft model. These results showed that LDHA is required for tumor progression where targeting cancer metabolism using small molecules provides a manner for controlling tumor growth.

As part of the responses of tumor metabolic stress, heat shock proteins (HSPs) are rapidly expressed, stress signals include a wide variety of physiological and environmental insults, which are proven to be essential for survival, this protective mechanism is usually referred as "Heat shock response" (HSR). Moreover, there is evidence that a wide range of human cancers exhibit an over-expression of HSPs providing a meaning for cell proliferation, differentiation, invasion, metastasis and evasion of the immune system (187). The HSF-1 transcriptional factor regulates the expression of HSPs but also regulates glucose metabolism by activating the expression of LDHA (188). In order to set the connection between HSR and LDH, an inhibitor of the LDH activity (Oxamate) by direct competition with its natural substrate was used in a hepatocellular carcinoma (HCC) derived cell model. Oxamate, was found to impact the constitutively activated HSR by reducing the levels of the HSP-27,-72, and-90 (181). Additionally, Galloflavin, hindered the ATPase activity of HSP 72 and 90, both compounds resulted in cell senescence. Taken together, the inhibition of LDH could be an efficient way to reduce the constitutively activated HSR in cancer cells by hindering the function of the three major molecular chaperones involved in tumorigenesis.

Targeting lactate metabolism as a therapeutic approach to defeat drug resistance has also been tested in different tumors. For instance, Das et al. (179) induced tamoxifen-resistant breast cancer cell lines (TAM-MCF-7 and -T47D) in order to establish a connection between LDHA and the induced pro-survival mechanism autophagy. The pharmacological and genetic inhibition of LDHA re-sensitized the TAM-resistant breast cancer cells to tamoxifen, but also inhibited the autophagy process therefore increasing cell death. These results provided a link between LDHA and Beclin-1, an important regulator of autophagy, in the induction of the cytoprotective autophagy of TAM-resistant breast cancer cells. Moreover, the depletion of LDHA reverted the EMT-like process attenuating the invasive and migratory properties of TAM-resistant cells. These results reveal that targeting the LDHA enzyme may be a novel strategy to combat glycolytic chemo-resistant cancers.

Given the importance of lactate metabolism in different types of cancers, the discovery and development of new molecules that could inhibit LDHA activity is urgently needed. Only a few molecules have started tests in clinical trials, for this reason there is a trend to optimize existing compounds, such is the case of compound 5, that was used as a template for molecular docking, then the 200 top-ranked compounds with the highest total binding scores were selected, however, only 1 molecule (compound 11: 11c) from 7 candidates was employed 
TABLE 2 | Approaches for inhibit lactate production and transport.

\begin{tabular}{|c|c|c|c|c|c|}
\hline Inhibitor(s) & Mechanism of action & Type of cancer or cell/animal model & $\begin{array}{l}\text { Research } \\
\text { phase }\end{array}$ & Limitations & References \\
\hline $\begin{array}{l}5 \text { designed peptides } \\
\text { (QLYNL, LIYNLL, IYNLLK, } \\
\text { KWYNVA, and KWYNV) }\end{array}$ & $\begin{array}{l}\text { LDHA tetramerization inhibition, affecting the } \\
\text { activity of the enzyme }\end{array}$ & None & In silico modeling & $\begin{array}{l}\text { In vivo investigation of these peptides on cancer cell } \\
\text { lines is needed to evaluate their biological potential }\end{array}$ & (176) \\
\hline Compound 24 & $\begin{array}{l}24 c \text { interacts directly with the binding pocket } \\
\text { of } L D H A \text { affecting the activity of the enzyme }\end{array}$ & Pancreas carcinoma (MiaPaCa-2) & Pre-clinical & $\begin{array}{l}\text { No limitations were shown, indeed } 24 \mathrm{c} \text { did not affect } \\
\text { the body weight of the mice, indicating low toxicity of } \\
\text { the compound }\end{array}$ & $(177)$ \\
\hline $\begin{array}{l}\text { 1-(Phenylseleno)- } \\
\text { 4-(Trifluoromethyl) Benzene } \\
\text { (PSTMB) }\end{array}$ & $\begin{array}{l}\text { This allosteric inhibitor of LDHA modifies the } \\
\text { pyruvate binding site due to conformational } \\
\text { changes on the enzyme by non-competition } \\
\text { inhibition }\end{array}$ & $\begin{array}{l}\text { Large cell lung cancer (NCI-H460) } \\
\text { Breast cancer (MCF-7) } \\
\text { Hepatocellular carcinoma (Hep3B) } \\
\text { Malignant melanoma (A375) } \\
\text { Colorectal adenocarcinoma (HT29) } \\
\text { Murine lung cancer cells (LLC) }\end{array}$ & Pre-clinical & $\begin{array}{l}\text { No limitations were shown, even in normal human } \\
\text { bronchial epithelial BEAS-2B cells, the cytotoxic } \\
\text { effect of PSTMB was limited }\end{array}$ & (178) \\
\hline $\begin{array}{l}\text { Oxamate } \\
\text { siRNA LDHA gene }\end{array}$ & $\begin{array}{l}\text { Oxamate is a non-competitive inhibitor which } \\
\text { has same the structure of pyruvate, this } \\
\text { compound inhibits LDHA activity } \\
\text { Small interfering RNA use to regulate the } \\
\text { expression of LDHA gene }\end{array}$ & Breast cancer (MCF-7 and T47D) & Pre-clinical & No limitations were shown & (179) \\
\hline Compounds 5 and 11 & $\begin{array}{l}\text { Both compounds maintain the same hydrogen } \\
\text { bond interactions with LDHA, however } 11 \mathrm{c} \\
\text { has extra interactions which could give rise to } \\
\text { its inhibitory activity against LDHA }\end{array}$ & Osteosarcoma (MG-63) & Pre-clinical & $\begin{array}{l}\text { No limitations were shown, however further } \\
\text { experiments with different cancer models are needed } \\
\text { to ensure its biological efficacy }\end{array}$ & (180) \\
\hline $\begin{array}{l}\text { Oxamate } \\
\text { Galloflavin }\end{array}$ & $\begin{array}{l}\text { Oxamate a non-competitive inhibitor hinders } \\
\text { LDH activity } \\
\text { Galloflavin inhibits human LDH isoforms } \\
\text { preferentially binding the free enzyme, without } \\
\text { competing with the substrate or cofactor }\end{array}$ & Liver cancer (PLC/PRF/5) & Pre-clinical & No limitations were shown & $(181)$ \\
\hline $\begin{array}{l}\text { siRNA LDHA gene } \\
\text { FX11 } \\
\text { FK866 }\end{array}$ & $\begin{array}{l}\text { Small interfering RNAs for knocking-down the } \\
\text { expression of LDHA gene } \\
\text { FX11 is a competitive inhibitor of LDHA } \\
\text { FK866 hinders the NAD } \\
\text { direct inhibition of Nicotinamide } \\
\text { Phosphoribosyl through } \\
\text { Prerase (NAMPT) }\end{array}$ & $\begin{array}{l}\text { B-lymphoid cells (P493) } \\
\text { Pancreatic cancer (P198) }\end{array}$ & Pre-clinical & $\begin{array}{l}\text { The combination of both compounds was toxic for } \\
\text { P493 cells causing a reduction of mitochondrial } \\
\text { membrane potential resulting in profound inhibition of } \\
\text { cell proliferation } \\
\text { In the in vivo assay, animals treated only with FX11 } \\
\text { did not lose weight or showed any alterations in } \\
\text { blood and chemistry studies. However, two of five } \\
\text { studied animals treated with FK866 did show mild } \\
\text { thrombocytopenia. Remarkably, the combination of } \\
\text { FX11 and FK866 increased BUN }\end{array}$ & (68) \\
\hline AZD3965 & $\begin{array}{l}\text { Selective inhibitor of human MCT1 with } \\
\text { additional activity against MCT2 } \\
\text { This compound hinders lactate transport, } \\
\text { consequently increasing intracellular levels } \\
\text { followed by glycolytic feedback and increased } \\
\text { flux into the TCA cycle }\end{array}$ & $\begin{array}{l}\text { Human diffuse large B-cell lymphomas } \\
\text { (HBL-1 and TMD8) } \\
\text { Human B-cell lymphoma (WSU-DLCL-2 } \\
\text { and SU-DHL10) } \\
\text { Lymphoblast (HT) } \\
\text { B-cell non-Hodgkin lymphoma } \\
\text { (Karpas-422 NHL) } \\
\text { Raji Burkitt's lymphoma cells }\end{array}$ & Pre-clinical & $\begin{array}{l}\text { This potent inhibitor of MCT1 showed a reduction in } \\
\text { growth of different cell lines especially hematological } \\
\text { types. Although the inhibitory effect, some types of } \\
\text { cancers express both transporters MCT1 and MCT4, } \\
\text { in this regard MCT4 may be continuing the lactate } \\
\text { transport suggesting a resistance to the } \\
\text { monotherapy }\end{array}$ & (182) \\
\hline
\end{tabular}


TABLE 2 | Continued

Inhibitor(s)

Mechanism of action

Type of cancer or cell/animal model

Research

Limitations

References

AR-C155858

Selective monocarboxylate transporter (MCT1 Murine breast cancer cell line, 4T1

Pre-clinical

No limitations were shown

$(183)$

and MCT2) which affects lactate uptake in

time dependent manner with slow reversible

features

$\mathrm{CHC}$

$\mathrm{CHC}$ inhibits different MCT isoforms, namely

( $\alpha$-cyano-4-hydroxycinnamic MCT1 as a primary target. This compound

acid) interacts with the outside proteins of the

DIDS membrane affecting lactate efflux,

(4,4'-diisothiocyanatostilbene- consequently arresting glycolysis

2,2'-disulphonic acid) DIDS is a MCT1 inhibitor, the interaction

Quercetin between one of the isothiocyanate groups of

DIDS with a lysine residue of MCT1 could

affect the transporter activity

Quercetin is a MCT inhibitor, specifically MCT1

and MCT2, the lactate and proton transport

BAY-8002

promotes intracellular acidification

Selective inhibition MCT1 which potently

Hematopoietic malignancies, Raji, and

Pre-clinical

suppress bidirectional lactate transport

Daudi Burkitt lymphoma cells

limited antitumor efficacy was observed in the in

vivo models suggesting a limited effect of the MCT 1

blockage. Thus, cells exhibit a capability to adapt to long-term inhibition of MCT1

Only a small proportion of cell lines tested showed a

significant reduction of cell viability indicating the

necessity for testing MCT1 in clinical tests

Syrosingopine

Increases intracellular lactate due the inhibition HeLa, HAP1, HL60 cells, liver tumor

Pre-clinical

No limitations were shown 
for further biological validation (180). 11c maintains the same hydrogen bond interactions as compound 5 in the binding model and exhibits extra hydrogen bond interactions with the residues Asp 194 and Thr 247 in LDHA, which could give rise to its inhibitory activity against LDHA. The in vitro assays reveal the potential action of $11 \mathrm{c}$ in the metabolism of an osteosarcoma-derived cell line, MG-63. These cells exhibit a dose-response effect to 11c, where lactate formation significantly diminished with the subsequent extracellular acidification rate (ECAR) decrement, consistent with a poor lactate synthesis. In addition, the use of $11 \mathrm{c}$ upregulated the oxygen consumption rate (OCR) indicating a metabolic switch from lactate production to pyruvate consumption. In relation to cell proliferation, $11 \mathrm{c}$ promoted apoptosis in the same dose dependent manner, thus impacting cell proliferation. Taking together, compound 11 is a new potent LDHA inhibitor, demonstrated by its ability to induce the reprogramming of MG-63 cancer cells metabolism from glycolysis to mitochondrial respiration decreasing cell survival. Nevertheless, further experiments using different types of cancers are needed to ensure its biological efficacy.

As for the optimization of small molecules, compound $24 \mathrm{c}$ is a novel potent LDHA inhibitor obtained by a hit-to-lead optimization from an in-house library. 24c interacts directly into the binding pocket of LDHA, forming a direct hydrogen bond interaction with Asn137, Arg168, His192, and Gln99 of the enzyme causing a metabolic alteration by enhancing oxidative phosphorylation and reducing lactate formation in cancer cells, which might contribute to their anti-proliferation effect. In addition, this compound showed a reduction of cell growth as well as apoptosis and cell cycle arrest in a dose dependent manner against MiaPaCa-2 cells derived from pancreas carcinoma. Furthermore, 24c suppressed the tumor growth in the xenograft model. Additionally, the evaluation of the metabolic profile in MiaPaCa-2 cells treated by $24 \mathrm{c}$ exhibited a decreasing in ECAR and lactate production but an increased OCR value. Consequently, these observations suggested that $24 \mathrm{c}$ could be used as a lead pharmacophore for the development of new potent LDHA inhibitor (177).

Through a screening of novel inhibitors, Kim et al. (178) found several promising selenobenzene compounds with inhibitory effects on LDHA activity. The most potent inhibitor of the activity of LDHA was 1-(phenylseleno)- 4(trifluoromethyl) benzene (PSTMB), this compound acts as an allosteric inhibitor modifying the active site where pyruvate binds, trough conformational changes that lead to the inhibition of enzymatic activity. Experimental assays indicated that PSTMB inhibited cell proliferation in several tumor cell lines including lung cancer (NCI-H460), breast cancer (MCF-7), hepatocellular carcinoma (Hep3B), malignant melanoma (A375), colorectal adenocarcinoma (HT29) and murine lung cancer cells (LLC). Furthermore, PSTMB incremented ROS generation and reduced the stability of the mitochondria inducing intrinsic pathwaymediated apoptosis of cancer cells. Additionally, LDHA activity and lactate production were clearly reduced by PSTMB under hypoxic and normoxic conditions, this suppression was mainly mediated by the inhibition of the enzyme activity, and not by the regulation of its expression. Summarizing, this novel selenobenzene, PSTMB, was found to be a potent inhibitor of the human LDHA enzyme.

Recently, peptides have been used as new class of drugs for the treatment of different diseases including cancer (189191). Owing to the protein-protein interaction (PPI), peptides have been used as a novel and powerful tool in drug discovery. Recently, novel peptides aiming to disrupt the subunit association of LDHA during its tetramerization process have been designed through in silico methods, designed to impact the activity of the enzyme. These peptides were developed based on its active conformation and the interaction interface of LDHA subunits where the N-terminal arm (residues 5-17) acts as an anchor to maintain the position and distance between the two LDHA subunits. Thus, these new peptides mimic the anchoring of the LDHA subunits avoiding its tetramerization (176). These novel anti-cancer agents designed for therapy have promising advantages like low toxicity, ease of synthesis and high target specificity whereas the classical pharmalogical therapeutics. However, in vivo investigation of these peptides and its effects on cancer cell lines is needed to evaluate the biological potential.

\section{Targeting MCTs}

The inhibition of the MCTs has also been implemented as a therapeutic strategy. Although there are only few reports inhibiting specifically the MCT, these have showed promising results in different neoplasms.

The AR-C117977 was first identified as an immunomodulatory compound with antiproliferative properties on T lymphocytes, where the MCT1 was identified as its target (192). The AZD3965 is a derivate compound from AR-C117977 with potent inhibition of the MCT1 with additional activity against MCT2. The main action of the compound is the inhibition of lactate transport inducing an acute increase in intracellular lactate levels followed by glycolytic feedback and increased flux into the TCA cycle (182). This compound inhibited the proliferation of several lymphoma cell lines. Even, the combination of AZD3965 with other compounds like inhibitors of GLS1, doxorubicin or rituximab resulted in enhanced inhibition of cell growth and increased cell death in the tested cell lines (182). Nevertheless, the status of MCTs could be contributing to the observed inhibitory effect, thus the evaluation of MCTs expression in the tested models could provide better insights for inhibitory molecules.

The effect of AZD3965 was tested along with AR-C155858 in a murine breast cancer-derived cell line, 4T1 (183). The authors found that both compounds exhibited a time-dependent inhibition of lactate uptake and very importantly, this inhibition was slowly reversible, indicating that such effect could offer potential benefits in cancer treatment. Likewise, Amorim et al. (184) tested the antiproliferative effects of three compounds in colorectal cancer derived cells finding that colorectal cancer cells, HCT15 and RKO decreased its glycolytic rate and enhanced cell death in the presence of any of the probed molecules. Interestingly, the cytotoxic effect exerted by 5 fluoro-uracil was potentiated when using together with those drugs. Moreover, targeting MCT1 and MCT4 with syrosingopine in cell models 
from different cancer types, Bejamin et al. (186) found an increase in intracellular lactate in HeLa cells, and the liver mouse model showed reduction in lactate concentration in nodules after syrosingopine treatment. Importantly, an increase in lactate levels in serum from syrosingopine-treated mice and a synergistic effect to metformin anti-properties was shown.

A high throughput examination of over 3 million compounds measuring lactate import-dependent intracellular acidification identified BAY-8002 as a potential MCT1 inhibitor (185). Then, authors showed the antiproliferative properties in different cells lines, where Daudi and Raji cells were most affected by this compound. The in vivo testing of BAY-8002 determined its capacity to decrease tumor mass over time using different concentrations ranging from 40 to $160 \mathrm{mg} / \mathrm{kg}$, without affecting body weight. Importantly, chronically exposed cells developed resistance to MCT1 inhibition probably due to the increment of MCT2 and MCT4 expression in resistant cells indicating that different molecular mechanisms could be involved in treatment resistance.

\section{CONCLUDING REMARKS}

Lactate is not only considered as a waste product derived from fermentative cell metabolism, but instead is a powerful molecule that contributes to both, the onset and progression of cancer, favoring metastasis and tumor angiogenesis. In tumor microenvironment, lactate establishes metabolic coupling between cancer cells, immune cells and stromal cells, acting as an interchangeable metabolite in the tumor mass. Oxygen availability defines different metabolic phenotypes because their location within the tumor, where hypoxic central areas display a higher lactate concentration. Thus, the development of new tools for quantifying intra-tumoral molecules to trace lactate accumulation and consumption by tumors represents a huge challenge in cancer research.

\section{REFERENCES}

1. Hanahan D, Weinberg RA. The hallmarks of cancer. Cell. (2000) 100:57-70. doi: 10.1016/s0092-8674(00)81683-9

2. Hanahan D, Weinberg RA. Hallmarks of cancer: the next generation. Cell. (2011) 144:646-74. doi: 10.1016/j.cell.2011.02.013

3. Warburg O, Wind F, Negelein E. The metabolims of tumors in the body. $J$ Gen Physiol. (1927) 8:519-30. doi: 10.1085/jgp.8.6.519

4. Racker E. Bioenergetics and the problem of tumor growth. Am Sci. (1972) 60:56-63.

5. Vyas S, Zaganjor E, Haigis MC. Mitochondria and cancer. Cell. (2016) 166:555-66. doi: 10.1016/j.cell.2016.07.002

6. Liu Y, Murray-stewart T, Casero RA, Kagiampakis I, Jin L, Zhang J, et al. Targeting hexokinase 2 inhibition promotes radiosensitization in HPV16 E7induced cervical cancer and suppresses tumor growth. Int J Oncol. (2017) 50:2011-23. doi: 10.3892/ijo.2017.3979

7. Marshall MJ, Neal FE, Goldberg DM. Isoenzymes of hexokinase, 6phosphogluconate dehydrogenase, phosphoglucomutase and lactate dehydrogenase in uterine cancer. Br J Cancer. (1979) 40:380-90. doi: 10.1038/bjc.1979.192

8. Park SI, Suh DS, Kim S, Choi KU, Yoon M. Correlation between biological marker expression and F-fluorodeoxyglucose uptake in cervical cancer
Lactate participates also in the immune escape through the inhibition of lymphocytes activity and induces the M2 macrophage polarization associated to tumor progression. In addition, it is currently known that metabolic plasticity exhibited by tumors allows the development of treatment resistance mechanisms due to adaptation to metabolic changes, impacting the effect of anti-metabolic drugs. Thus, lactateinduced resistance to therapy represents the major obstacle in the elimination of malignant tumors. For this reason, it is necessary to pursuit for more studies aimed to determine synergistic combinations including lactate dehydrogenase and MCTs inhibitors for developing reliable and effective treatments in cancer.

\section{AUTHOR CONTRIBUTIONS}

KC-L and JM-M: conception and design. KC-L, LC-M, DR-H, AG-C, and JM-M: wrote and critically review the manuscript. KC-L, LC-M, DR-H, and JM-M: figure design and elaboration. JM-M: directed manuscript.

\section{FUNDING}

This work was partially supported by Instituto Nacional de Cancerología from Mexico references: (018/037/IBI)(CEI/1284/18) and (017/048/IBI)(CEI/1227/17).

\section{ACKNOWLEDGMENTS}

$\mathrm{KC}-\mathrm{L}$ and LC-M are students from the program Doctorado en Ciencias Biomédicas and DR-H belongs to the program Maestría y Doctorado en Ciencias Médicas, Odontológicas y de la Salud, at the Universidad Nacional Autónoma de México and are the recipients of scholarships from CONACyT, México (406537, 282303, and 638768, respectively).

measured by positron emission tomography. Onkologie. (2013) 36:169-74. doi: 10.1159/000349944

9. Jiao L, Zhang H, Li D, Yang K, Tang J, Li X, et al. Regulation of glycolytic metabolism by autophagy in liver cancer involves selective autophagic. Autophagy. (2017) 14:671-84. doi: 10.1080/15548627.2017.1381804

10. Wadsak W, Mitterhauser M. Basics and principles of radiopharmaceuticals for PET/CT. Eur J Radiol. (2010) 73:461-9. doi: 10.1016/j.ejrad.2009.12.022

11. Wang L, Xiong H, Wu F, Zhang Y, Wang J, Zhao L, et al. Article hexokinase 2-mediated warburg effect is required for PTEN - and p53 - deficiency-driven prostate cancer growth. Cell Rep. (2014) 8:1461-74. doi: 10.1016/j.celrep.2014.07.053

12. Wong N, Ojo D, Yan J, Tang D. PKM2 contributes to cancer metabolism. Cancer Lett. (2015) 356:184-91. doi: 10.1016/j.canlet.2014.01.031

13. Mayer A, Schmidt M, Seeger A, Serras AF, Vaupel P, Schmidberger H. GLUT1 expression is largely unrelated to both hypoxia and the Warburg phenotype in squamous cell carcinomas of the vulva. BMC Cancer. (2014) 14:760. doi: 10.1186/1471-2407-14-760

14. Fantin VR, St.-Pierre J, Leder P. Attenuation of LDH-A expression uncovers a link between glycolysis, mitochondrial physiology, and tumor maintenance. Cancer Cell. (2006) 9:425-34. doi: 10.1016/j.ccr.2006.04.023

15. Shim H, Dolde C, Lewis BC, Wu C-S, Dang G, Jungmann RA, et al. cMyc transactivation of LDH-A: implications for tumor metabolism and 
growth. Proc Natl Acad Sci USA. (1997) 94:6658-63. doi: 10.1073/pnas.94. 13.6658

16. Johnson RF, Perkins ND. Nuclear factor- $\mathrm{kB}$, p53, and mitochondria: regulation of cellular metabolism and the Warburg effect. Trends Biochem Sci. (2012) 37:317-24. doi: 10.1016/j.tibs.2012.04.002

17. Lu H, Forbes RA, Verma A. Hypoxia-inducible factor 1 activation by aerobic glycolysis implicates the Warburg effect in carcinogenesis. J Biol Chem. (2002) 277:23111-5. doi: 10.1074/jbc.M202487200

18. Levine AJ, Puzio-Kuter AM. The control of the metabolic switch in cancers by oncogenes and tumor suppressor genes. Science. (2010) 330:1340-4. doi: 10.1126/science.1193494

19. San-Millán I, Brooks GA. Reexamining cancer metabolism: lactate production for carcinogenesis could be the purpose and explanation of the Warburg Effect. Carcinogenesis. (2017) 38:119-33. doi: 10.1093/carcin/bgw127

20. Lyssiotis CA, Kimmelman AC. Metabolic interactions in the tumor microenvironment. Trends Cell Biol. (2017) 27:863-75. doi: 10.1016/j.tcb.2017.06.003

21. Talasniemi JP, Pennanen S, Savolainen H, Niskanen L, Liesivuori J. Analytical investigation: assay of d-lactate in diabetic plasma and urine. Clin Biochem. (2008) 41:1099-103. doi: 10.1016/J.CLINBIOCHEM.2008.06.011

22. Connor H, Woods HF, Ledingham JG. Comparison of the kinetics and utilisation of D(-)-and L(+)-sodium lactate in normal man. Ann Nutr Metab. (1983) 27:481-7. doi: 10.1159/000176723

23. Nalbandian $M$, Takeda $M$. Lactate as a signaling molecule that regulates exercise-induced adaptations. Biology. (2016) 5:38. doi: $10.3390 /$ biology 5040038

24. Gladden LB. Lactate metabolism: a new paradigm for the third millennium. J Physiol. (2004) 558:5-30. doi: 10.1113/jphysiol.2003.058701

25. Neufeld EF, Ginsburg V. Carbohydrate metabolism. Annu Rev Biochem. (1965) 34:297-312. doi: 10.1146/annurev.bi.34.070165.001501

26. Consoli A, Nurjhan N, Reilly JJ, Bier DM, Gerich JE. Contribution of liver and skeletal muscle to alanine and lactate metabolism in humans. Am J Physiol Metab. (2017) 259:E677-84. doi: 10.1152/ajpendo.1990.259.5.e677

27. Brooks GA. Lactate: Glycolytic end Product and Oxidative Substrate During Sustained Exercise in Mammals-The 'Lactate Shuttle'. Berlin, Heidelberg: Springer.

28. Brooks GA. Cell-cell and intracellular lactate shuttles. J Physiol. (2009) 587:5591-600. doi: 10.1113/jphysiol.2009.178350

29. Brooks GA. The science and translation of lactate shuttle theory. Cell Metab. (2018) 27:757-85. doi: 10.1016/j.cmet.2018.03.008

30. Walenta S, Wetterling M, Lehrke M, Schwickert G, Sundfør K, Rofstad EK, et al. High lactate levels predict likelihood of metastases, tumor recurrence, and restricted patient survival in human cervical cancers. Cancer Res. (2000) 60:916-21.

31. Brizel DM, Clough RW, Dewhirst MW, Schroeder T, Walenta S, MuellerKlieser W, et al. Elevated tumor lactate concentrations predict for an increased risk of metastases in head-and-neck cancer. Int J Radiat Oncol Biol Phys. (2001) 51:349-53. doi: 10.1016/S0360-3016(01)01630-3

32. Walenta S, Salameh A, Lyng H, Evensen JF, Mitze M, Rofstad EK, et al. Correlation of high lactate levels in head and neck tumors with incidence of metastasis. Am J Pathol. (1997) 150:409-15.

33. Walenta S, Van Chau T, Schroeder T, Lehr HA, Kunz-Schughart LA, Fuerst A, et al. Metabolic classification of human rectal adenocarcinomas: a novel guideline for clinical oncologists? J Cancer Res Clin Oncol. (2003) 129:321-6. doi: $10.1007 / \mathrm{s} 00432-003-0450-\mathrm{x}$

34. Kennedy KM, Scarbrough PM, Ribeiro A, Richardson R, Yuan H, Sonveaux P, et al. Catabolism of exogenous lactate reveals it as a legitimate metabolic substrate in breast cancer. PLoS ONE. (2013) 8:e75154. doi: 10.1371/journal.pone.0075154

35. Vlachostergios PJ, Oikonomou KG, Gibilaro E, Apergis G. Elevated lactic acid is a negative prognostic factor in metastatic lung cancer. Cancer Biomarkers. (2015) 15:725-34. doi: 10.3233/CBM-150514

36. Nikoobakht M, Shamshiripour P, Azimi Nekoo Z, Fallah Haghmohammadi S. Elevated lactate and total protein levels in stereotactic brain biopsy specimen: potential biomarkers of malignancy and poor prognosis. Arch Iran Med. (2019) 22:125-31.
37. Quennet V, Yaromina A, Zips D, Rosner A, Walenta S, Baumann M, et al. Tumor lactate content predicts for response to fractionated irradiation of human squamous cell carcinomas in nude mice. Radiother Oncol. (2006) 81:130-5. doi: 10.1016/j.radonc.2006.08.012

38. Tamulevicius P, Streffer C. Metabolic imaging in tumours by means of bioluminescence. Br J Cancer. (1995) 72:1102-12. doi: 10.1038/bjc.1995.472

39. Liberti MV, Locasale JW. The warburg effect : how does it benefit cancer cells? Trends Biochem Sci. (2016) 41:211-8. doi: 10.1016/j.tibs.2015.12.001

40. Van Der Bliek AM, Sedensky MM, Morgan PG. Cell biology of the mitochondrion. Genetics. (2017) 207:843-71. doi: 10.1534/genetics.117.300262

41. DeBerardinis RJ, Mancuso A, Daikhin E, Nissim I, Yudkoff M, Wehrli $S$, et al. Beyond aerobic glycolysis: transformed cells can engage in glutamine metabolism that exceeds the requirement for protein and nucleotide synthesis. Proc Natl Acad Sci USA. (2007) 104:19345-50. doi: 10.1073/pnas.0709747104

42. Cruzat V, Rogero MM, Keane KN, Curi R, Newsholme P. Glutamine: metabolism and immune function, supplementation and clinical translation. Nutrients. (2018) 10:1-31. doi: 10.3390/nu10111564

43. Reitzer LJ, Wice BM, Kennell D. Evidence that glutamine, not sugar, is the major energy source for cultured HeLa cells. J Biol Chem. (1979) 254:266976.

44. Anderson NM, Mucka P, Kern JG, Feng H. The emerging role and targetability of the TCA cycle in cancer metabolism. Protein Cell. (2018) 9:216-37. doi: 10.1007/s13238-017-0451-1

45. Zacksenhaus E, Shrestha M, Liu JC, Vorobieva I, Chung PED, Ju YJ, et al. Mitochondrial OXPHOS induced by RB1 deficiency in breast cancer: implications for anabolic metabolism, stemness, and metastasis. Trends Cancer. (2017) 3:768-79. doi: 10.1016/j.trecan.2017.09.002

46. Santidrian AF, Matsuno-yagi A, Ritland M, Seo BB, Leboeuf SE, Gay LJ, et al. Mitochondrial complex I activity and NAD+/NADH balance regulate breast cancer progression. J Clin Invest. (2013) 123:1068-81. doi: 10.1172/JCI64264DS1

47. Chen YJ, Mahieu NG, Huang X, Singh M, Crawford PA, Johnson SL, et al. Lactate metabolism is associated with mammalian mitochondria. Nat Chem Biol. (2016) 12:937-43. doi: 10.1038/nchembio.2172

48. Hashimoto T, Hussien R, Brooks GA. Colocalization of MCT1, CD147, and LDH in mitochondrial inner membrane of L6 muscle cells: evidence of a mitochondrial lactate oxidation complex. Am J Physiol Metab. (2006) 290:E1237-44. doi: 10.1152/ajpendo.00594.2005

49. Hashimoto T, Hussien R, Cho HS, Kaufer D, Brooks GA. Evidence for the mitochondrial lactate oxidation complex in rat neurons: demonstration of an essential component of brain lactate shuttles. PLoS ONE. (2008) 3:2915. doi: 10.1371/journal.pone.0002915

50. Gallagher CN, Carpenter KLH, Grice P, Howe DJ, Mason A, Timofeev I, et al. The human brain utilizes lactate via the tricarboxylic acid cycle: a 13C-labelled microdialysis and high-resolution nuclear magnetic resonance study. Brain. (2009) 132:2839-49. doi: 10.1093/brain/awp202

51. Hirayama A, Kami K, Sugimoto M, Sugawara M, Toki N, Onozuka $\mathrm{H}$, et al. Quantitative metabolome profiling of colon and stomach cancer microenvironment by capillary electrophoresis time-of-flight mass spectrometry. Cancer Res. (2009) 69:4918-25. doi: 10.1158/0008-5472.CAN-08-4806

52. Hui S, Ghergurovich JM, Morscher RJ, Jang C, Teng X, Lu W, et al. Glucose feeds the TCA cycle via circulating lactate. Nature. (2017) 551:115-8. doi: 10.1038/nature24057

53. Sonveaux P, Feron O, Dewhirst MW, Sonveaux P, Végran F, Schroeder T, et al. Targeting lactate-fueled respiration selectively kills hypoxic tumor cells in mice. J Clin Invest. (2008) 118:3930-42. doi: 10.1172/JCI36843

54. Park S, Chang CY, Safi R, Liu X, Baldi R, Jasper JS, et al. ERR $\alpha-$ regulated lactate metabolism contributes to resistance to targeted therapies in breast cancer. Cell Rep. (2016) 15:323-35. doi: 10.1016/j.celrep.2016. 03.026

55. Leithner K, Hrzenjak A, Trötzmüller M, Moustafa T, Köfeler HC, Wohlkoenig C, et al. PCK2 activation mediates an adaptive response to glucose depletion in lung cancer. Oncogene. (2015) 34:1044-50. doi: 10.1038/onc.2014.47 
56. Faubert B, Li KY, Cai L, Hensley CT, Kim J, Zacharias LG, et al. Lactate metabolism in human lung tumors. Cell. (2017) 171:358-71. doi: 10.1016/j.cell.2017.09.019

57. Bok R, Lee J, Sriram R, Keshari K, Sukumar S, Daneshmandi S, et al. The role of lactate metabolism in prostate cancer progression and metastases revealed by dual-agent hyperpolarized ${ }^{13} \mathrm{C}$ MRSI. Cancers. (2019) 11:257. doi: 10.3390/cancers 11020257

58. Le A, Lane AN, Hamaker M, Bose S, Gouw A, Barbi J, et al. Glucose-independent glutamine metabolism via TCA cycling for proliferation and survival in B cells. Cell Metab. (2012) 15:110-21. doi: 10.1016/j.cmet.2011.12.009

59. Pérez-Escuredo J, Dadhich RK, Dhup S, Cacace A, Van Hée VF, De Saedeleer CJ, et al. Lactate promotes glutamine uptake and metabolism in oxidative cancer cells. Cell Cycle. (2016) 15:72-83. doi: 10.1080/15384101.2015.1120930

60. Adeva-Andany M, López-Ojén M, Funcasta-Calderón R, AmeneirosRodríguez E, Donapetry-García C, Vila-Altesor M, et al. Comprehensive review on lactate metabolism in human health. Mitochondrion. (2014) 17:76100. doi: 10.1016/j.mito.2014.05.007

61. Liang X, Liu L, Fu T, Zhou Q, Zhou D, Xiao L, et al. Exercise inducible lactate dehydrogenase B regulates mitochondrial function in skeletal muscle. J Biol Chem. (2016) 291:25306-18. doi: 10.1074/jbc.M116.749424

62. Dawson DM, Goodfriend TL, Kaplan NO. Lactic dehydrogenases: functions of the two types rates of synthesis of the two major forms can. Science. (2013) 143:929-33. doi: 10.2307/1712825

63. Belenky P, Bogan KL, Brenner C. NAD+ metabolism in health and disease. Trends Biochem Sci. (2007) 32:12-9. doi: 10.1016/j.tibs.2006.11.006

64. Fu Y, Lan T, Cai H, Lu A, Yu W. Meta-analysis of serum lactate dehydrogenase and prognosis for osteosarcoma. Medicine. (2018) 97:1-9. doi: 10.1097/MD.0000000000010741

65. Gan J, Wang W, Yang Z, Pan J, Zheng L, Yin L. Prognostic value of pretreatment serum lactate dehydrogenase level in pancreatic cancer patients. Medicine. (2018) 97:e13151. doi: 10.1097/md.0000000000013151

66. Zhang Z, Li Y, Yan X, Song Q, Wang G, Hu Y, et al. Pretreatment lactate dehydrogenase may predict outcome of advanced non small-cell lung cancer patients treated with immune checkpoint inhibitors: a meta-analysis. Cancer Med. (2019) 8:1467-73. doi: 10.1002/cam4.2024

67. Hou X, Yuan S, Zhao D, Liu X, Wu X. LDH-A promotes malignant behavior via activation of epithelial-to-mesenchymal transition in lung adenocarcinoma. Biosci Rep. (2019) 39:BSR20181476. doi: 10.1042/bsr20181476

68. Le A, Cooper CR, Gouw AM, Dinavahi R, Maitra A, Deck LM, et al. Inhibition of lactate dehydrogenase A induces oxidative stress and inhibits tumor progression. Proc Natl Acad Sci USA. (2010) 107:2037-42. doi: 10.1073/pnas.0914433107

69. Chaudhari V, Pradeep G, Prakash N, Mahajan A. Estimation of salivary sialic acid in oral premalignancy and oral squamous cell carcinoma. Contemp Clin Dent. (2016) 7:451. doi: 10.4103/0976-237x.194108

70. Saluja TS, Spadigam A, Dhupar A, Syed S. Equating salivary lactate dehydrogenase (LDH) with LDH-5 expression in patients with oral squamous cell carcinoma: an insight into metabolic reprogramming of cancer cell as a predictor of aggressive phenotype. Tumor Biol. (2016) 37:5609-20. doi: 10.1007/s13277-015-4415-x

71. Mohajertehran F, Ayatollahi H, Jafarian AH, Khazaeni K, Soukhtanloo M, Shakeri M-T, et al. Overexpression of lactate dehydrogenase in the saliva and tissues of patients with head and neck squamous cell carcinoma. Rep Biochem Mol Biol. (2019) 7:1413-9. doi: 10.1002/hed.21618

72. Fan J, Hitosugi T, Chung T-W, Xie J, Ge Q, Gu T-L, et al. Tyrosine phosphorylation of lactate dehydrogenase A is important for NADH/NAD+ redox homeostasis in cancer cells. Mol Cell Biol. (2011) 31:4938-50. doi: $10.1128 / \mathrm{mcb} .06120-11$

73. Liu J, Chen G, Liu Z, Liu S, Cai Z, You P, et al. Aberrant FGFR tyrosine kinase signaling enhances the warburg effect by reprogramming $\mathrm{LDH}$ isoform expression and activity in prostate cancer. Cancer Res. (2018) 78:4459-70. doi: 10.1158/0008-5472.CAN-17-3226

74. Jin L, Chun J, Pan C, Alesi GN, Li D, Magliocca KR, et al. Phosphorylationmediated activation of LDHA promotes cancer cell invasion and tumour metastasis. Oncogene. (2017) 36:3797-806. doi: 10.1038/onc.2017.6
75. Li S, Gao J, Zhuang X, Zhao C, Hou X, Xing X, et al. Cyclin G2 inhibits the warburg effect and tumour progression by suppressing LDHA phosphorylation in glioma. Int J Biol Sci. (2019) 15:544-55. doi: 10.7150/ijbs.30297

76. Linster CL, Van Schaftingen E, Hanson AD. Metabolite damage and its repair or pre-emption. Nat Chem Biol. (2013) 9:72-80. doi: 10.1038/nchembio.1141

77. Intlekofer AM, DeMatteo RG, Venneti S, Finley LWS, Lu C, Judkins AR, et al. Hypoxia induces production of L-2-hydroxyglutarate. Cell Metab. (2015) 22:304-11. doi: 10.1016/j.cmet.2015.06.023

78. Intlekofer AM, Wang B, Liu H, Shah H, Carmona-Fontaine C, Rustenburg AS, et al. L-2-Hydroxyglutarate production arises from noncanonical enzyme function at acidic pH. Nat Chem Biol. (2017) 13:494-500. doi: $10.1038 /$ nchembio. 2307

79. Wykoff CC, Pugh CW, Harris AL, Maxwell PH, Ratcliffe PJ. The HIF pathway: implications for patterns of gene expression in cancer. Novartis Found Symp. (2001) 240:212-25. doi: 10.1002/0470868716.ch15

80. Semenza GL, Jiang BH, Leung SW, Passantino R, Concordat JP, Maire $\mathrm{P}$, et al. Hypoxia response elements in the aldolase $\mathrm{A}$, enolase 1 , and lactate dehydrogenase a gene promoters contain essential binding sites for hypoxia-inducible factor 1. J Biol Chem. (1996) 271:32529-37. doi: $10.1074 /$ jbc.271.51.32529

81. Liu Y, Guo JZ, Liu Y, Wang K, Ding W, Wang H, et al. Nuclear lactate dehydrogenase A senses ROS to produce $\alpha$-hydroxybutyrate for HPV-induced cervical tumor growth. Nat Commun. (2018) 9:4429. doi: 10.1038/s41467-018-06841-7

82. Trivedi B, Danforth WH. Effect of $\mathrm{pH}$ on the kinetics of frog muscle phosphofructokinase. J Biol Chem. (1966) 241:4110-2.

83. Jones R, Morris M. Monocarboxylate transporters: therapeutic targets and prognostic factors in disease. Clin Pharmacol Ther. (2016) 100:454-63. doi: $10.1002 /$ cpt.418

84. Garcia CK, Goldstein JL, Pathak RK, Anderson RGW, Brown MS. Molecular characterization of a membrane transporter for lactate, pyruvate, and other monocarboxylates: implications for the Cori cycle. Cell. (1994) 76:865-73. doi: 10.1016/0092-8674(94)90361-1

85. Spencer TL, Lehninger AL. L-lactate transport in Ehrlich ascites-tumour cells. Biochem J. (1976) 154:405-14. doi: 10.1042/bj1540405

86. Kirk P, Wilson MC, Heddle C, Brown MH, Barclay AN, Halestrap AP. CD147 is tightly associated with lactate transporters MCT1 and MCT4 and facilitates their cell surface expression. EMBO J. (2000) 19:3896-904. doi: 10.1093/emboj/19.15.3896

87. Wilson MC, Meredith D, Manning Fox JE, Manoharan C, Davies AJ, Halestrap AP. Basigin (CD147) is the target for organomercurial inhibition of monocarboxylate transporter isoforms 1 and 4: the ancillary protein for the insensitive MCT2 is embigin (gp70). J Biol Chem. (2005) 280:27213-21. doi: 10.1074/jbc.M411950200

88. Gallagher SM, Castorino JJ, Wang D, Philp NJ. Monocarboxylate transporter 4 regulates maturation and trafficking of CD147 to the plasma membrane in the metastatic breast cancer cell line MDA-MB-231. Cancer Res. (2007) 67:4182-9. doi: 10.1158/0008-5472.CAN-06-3184

89. Updegraff BL, Zhou X, Guo Y, Padanad MS, Chen PH, Yang C, et al. Transmembrane protease TMPRSS11B promotes lung cancer growth by enhancing lactate export and glycolytic metabolism. Cell Rep. (2018) 25:2223-2233.e6. doi: 10.1016/j.celrep.2018.10.100

90. Pinheiro C, Morais-Santos F, Baltazar F, Longatto-Filho A, Garcia EA, Scapulatempo-Neto C, et al. Lactate transporters and vascular factors in HPV-induced squamous cell carcinoma of the uterine cervix. BMC Cancer. (2014) 14:1-12. doi: 10.1186/1471-2407-14-751

91. Fang J, Quinones QJ, Holman TL, Morowitz MJ, Wang Q, Zhao H, et al. The H+-linked monocarboxylate transporter (MCT1/SLC16A1): a potential therapeutic target for high-risk neuroblastoma. Mol Pharmacol. (2006) 70:2108-15. doi: 10.1124/mol.106.026245

92. Kim Y, Choi JW, Lee JH, Kim YS. Expression of lactate/H+ symporters MCT1 and MCT4 and their chaperone CD147 predicts tumor progression in clear cell renal cell carcinoma: immunohistochemical and the Cancer Genome Atlas data analyses. Hum Pathol. (2015) 46:104-12. doi: 10.1016/j.humpath.2014.09.013

93. Curry JM, Tuluc M, Whitaker-Menezes D, Ames JA, Anantharaman A, Butera A, et al. Cancer metabolism, stemness and tumor recurrence : MCT1 
and MCT4 are functional biomarkers of metabolic symbiosis in head and neck cancer. Cell Cycle. (2013) 12:1371-84. doi: 10.4161/cc.24092

94. Zhang G, Zhang Y, Dong D, Wang F, Ma X, Guan F, et al. MCT1 regulates aggressive and metabolic phenotypes in bladder cancer. J Cancer. (2018) 9:2492-501. doi: 10.7150/jca.25257

95. Pinheiro C, Longatto-Filho A, Pereira SMM, Etlinger D, Moreira MAR, Jubé LF, et al. Monocarboxylate transporters 1 and 4 are associated with CD147 in cervical carcinoma. Dis Markers. (2009) 26:97-103. doi: 10.3233/DMA-2009-0596

96. Pinheiro C, Miranda-Gonçalves V, Longatto-Filho A, Vicente ALSA, Berardinelli GN, Scapulatempo-Neto C, et al. The metabolic microenvironment of melanomas: prognostic value of MCT1 and MCT4. Cell Cycle. (2016) 15:1462-70. doi: 10.1080/15384101.2016.1175258

97. Payen VL, Hsu MY, Rädecke KS, Wyart E, Vazeille T, Bouzin C, et al. Monocarboxylate transporter MCT1 promotes tumor metastasis independently of its activity as a lactate transporter. Cancer Res. (2017) 77:5591-601. doi: 10.1158/0008-5472.CAN-17-0764

98. Gerlinger M, Santos CR, Spencer-Dene B, Martinez P, Endesfelder D, Burrell RA, et al. Genome-wide RNA interference analysis of renal carcinoma survival regulators identifies MCT4 as a Warburg effect metabolic target. $J$ Pathol. (2012) 227:146-56. doi: 10.1002/path.4006

99. Choi SYC, Ettinger SL, Lin D, Xue H, Ci X, Nabavi N, et al. Targeting MCT4 to reduce lactic acid secretion and glycolysis for treatment of neuroendocrine prostate cancer. Cancer Med. (2018) 7:3385-92. doi: 10.1002/cam4.1587

100. Bisetto S, Whitaker-Menezes D, Wilski NA, Tuluc M, Curry J, Zhan T, et al. Monocarboxylate transporter 4 (MCT4) knockout mice have attenuated $4 \mathrm{NQO}$ induced carcinogenesis; a role for MCT4 in driving oral squamous cell cancer. Front Oncol. (2018) 8:1-13. doi: 10.3389/fonc.2018.00324

101. Ippolito L, Morandi A, Giannoni E, Chiarugi P. Lactate: a metabolic driver in the tumour landscape. Trends Biochem Sci. (2019) 44:153-66. doi: 10.1016/j.tibs.2018.10.011

102. Morandi A, Giannoni E, Chiarugi P. Nutrient exploitation within the tumor-stroma metabolic crosstalk. Trends Cancer. (2016) 2:736-46. doi: 10.1016/j.trecan.2016.11.001

103. García-Cañaveras JC, Chen L, Rabinowitz JD. The tumor metabolic microenvironment: lessons from lactate. Cancer Res. (2019) 2019:3276. doi: 10.1158/0008-5472.can-18-3726

104. Estrella V, Chen T, Lloyd M, Wojtkowiak J, Cornnell HH, Ibrahim-Hashim A, et al. Acidity generated by the tumor microenvironment drives local invasion. Cancer Res. (2013) 73:1524-35. doi: 10.1158/0008-5472.CAN-12-2796

105. Lee SH, McIntyre D, Honess D, Hulikova A, Pacheco-Torres J, Cerdán S, et al. Carbonic anhydrase IX is a pH-stat that sets an acidic tumour extracellular pH in vivo. Br J Cancer. (2018) 119:622-30. doi: 10.1038/s41416-018-0216-5

106. Pastorek J, Pastoreková S, Callebaut I, Mornon JP, Zelník V, Opavský R, et al. Cloning and characterization of $\mathrm{MN}$, a human tumor-associated protein with a domain homologous to carbonic anhydrase and a putative helix-loop-helix DNA binding segment. Oncogene. (1994) 9:2877-88.

107. Büscheck F, Fraune C, Simon R, Kluth M, Hube-Magg C, Möller-Koop C, et al. Aberrant expression of membranous carbonic anhydrase IX (CAIX) is associated with unfavorable disease course in papillary and clear cell renal cell carcinoma. Urol Oncol Semin Orig Investig. (2018) 36:531.e19-25. doi: 10.1016/j.urolonc.2018.08.015

108. Panisova E, Kery M, Sedlakova O, Brisson L, Debreova M, Sboarina $\mathrm{M}$, et al. Lactate stimulates CA IX expression in normoxic cancer cells. Oncotarget. (2017) 8:77819-35. doi: 10.18632/oncotarget. 20836

109. Klier M, Schüler C, Halestrap AP, Sly WS, Deitmer JW, Becker HM. Transport activity of the high-affinity monocarboxylate transporter MCT2 is enhanced by extracellular carbonic anhydrase IV but not by intracellular carbonic anhydrase II. J Biol Chem. (2011) 286:27781-91. doi: 10.1074/jbc.M111.255331

110. Jamali S, Klier M, Ames S, Felipe Barros L, McKenna R, Deitmer JW, et al. Hypoxia-induced carbonic anhydrase IX facilitates lactate flux in human breast cancer cells by non-catalytic function. Sci Rep. (2015) 5:1-16. doi: 10.1038/srep 13605

111. Ames S, Pastorekova S, Becker HM. The proteoglycan-like domain of carbonic anhydrase IX mediates non-catalytic facilitation of lactate transport in cancer cells. Oncotarget. (2018) 9:27940-57. doi: 10.18632 /oncotarget.25371

112. Forero-Quintero LS, Ames S, Schneider HP, Thyssen A, Boone CD, Andring JT, et al. Membrane-anchored carbonic anhydrase IV interacts with monocarboxylate transporters via their chaperones CD147 and GP70. J Biol Chem. (2019) 294:593-607. doi: 10.1074/jbc.RA118.005536

113. Hensley CT, Faubert B, Yuan Q, Lev-Cohain N, Jin E, Kim J, et al. Metabolic heterogeneity in human lung tumors. Cell. (2016) 164:681-94. doi: 10.1016/j.cell.2015.12.034

114. Ullah MS, Davies AJ, Halestrap AP. The plasma membrane lactate transporter MCT4, but not MCT1, is up-regulated by hypoxia through a HIF-1 $\alpha$-dependent mechanism. J Biol Chem. (2006) 281:9030-7. doi: 10.1074/jbc.M511397200

115. Dimmer KS, Friedrich B, Lang F, Deitmer JW, Bröer S. The low-affinity monocarboxylate transporter MCT4 is adapted to the export of lactate in highly glycolytic cells. Biochem J. (2000) 350:219-27. doi: 10.1042/bj3500219

116. Baek GH, Tse YF, Hu Z, Cox D, Buboltz N, McCue P, et al. MCT4 defines a glycolytic subtype of pancreatic cancer with poor prognosis and unique metabolic dependencies. Cell Rep. (2014) 9:2233-49. doi: 10.1016/j.celrep.2014.11.025

117. Pavlova NN, Thompson CB. Perspective The emerging hallmarks of cancer metabolism. Cell Metab. (2016) 23:27-47. doi: 10.1016/j.cmet.2015.12.006

118. Bonuccelli G, Tsirigos A, Whitaker-Menezes D, Pavlides S, Pestell RG, Chiavarina B, et al. Ketones and lactate "fuel" tumor growth and metastasis: evidence that epithelial cancer cells use oxidative mitochondrial metabolism. Cell Cycle. (2010) 9:3506-14. doi: 10.4161/cc.9.17.12731

119. Shan T, Chen S, Chen X, Lin WR, Li W, Ma J, et al. CancerAssociated fibroblasts enhance pancreatic cancer cell invasion by remodeling the metabolic conversion mechanism. Oncol Rep. (2017) 37:1971-9. doi: 10.3892/or.2017.5479

120. Martinez-Outschoorn UE, Lin Z, Trimmer C, Flomenberg N, Wang $\mathrm{C}$, Pavlides S, et al. Cancer cells metabolically "fertilize" the tumor microenvironment with hydrogen peroxide, driving the Warburg effect: implications for PET imaging of human tumors. Cell Cycle. (2011) 10:250420. doi: $10.4161 /$ cc.10.15.16585

121. Kimmelman AC, White E. Autophagy and tumor metabolism. Cell Metab. (2017) 25:1037-43. doi: 10.1016/j.cmet.2017.04.004

122. Whitaker-Menezes D, Martinez-Outschoorn UE, Flomenberg N, Birbe RC, Witkiewicz AK, Howell A, et al. Hyperactivation of oxidative mitochondrial metabolism in epithelial cancer cells in situ: visualizing the therapeutic effects of metformin in tumor tissue. Cell Cycle. (2011) 10:4047-64. doi: $10.4161 / \mathrm{cc} \cdot 10.23 .18151$

123. Luo M, Luo Y, Mao N, Huang G, Teng C, Wang H, et al. Cancerassociated fibroblasts accelerate malignant progression of non-small cell lung cancer via connexin 43-formed unidirectional gap junctional intercellular communication. Cell Physiol Biochem. (2018) 51:315-36. doi: $10.1159 / 000495232$

124. Zhou W, Xu G, Wang Y, Xu Z, Liu X, Xu X, et al. Oxidative stress induced autophagy in cancer associated fibroblast enhances proliferation and metabolism of colorectal cancer cells. Cell Cycle. (2017) 16:73-81. doi: $10.1080 / 15384101.2016 .1252882$

125. Sun K, Tang S, Hou Y, Xi L, Chen Y, Yin J, et al. Oxidized ATM-mediated glycolysis enhancement in breast cancer-associated fibroblasts contributes to tumor invasion through lactate as metabolic coupling. EBio Med. (2019) 41:370-83. doi: 10.1016/j.ebiom.2019.02.025

126. Fiaschi T, Marini A, Giannoni E, Taddei ML, Gandellini P, De Donatis A, et al. Reciprocal metabolic reprogramming through lactate shuttle coordinately influences tumor-stroma interplay. Cancer Res. (2012) 72:513040. doi: 10.1158/0008-5472.CAN-12-1949

127. Fu Y, Liu S, Yin S, Niu W, Xiong W, Tan M, et al. The reverse Warburg effect is likely to be an Achilles' heel of cancer that can be exploited for cancer therapy. Oncotarget. (2017) 8:57813-25. doi: 10.18632/oncotarget.18175

128. Davies M. New modalities of cancer treatment for NSCLC: focus on immunotherapy. Cancer Manag Res. (2014) 6:63-75. doi: 10.2147/CMAR.S57550

129. Gonzalez H, Hagerling C, Werb Z. Roles of the immune system in cancer: from tumor initiation to metastatic progression. Genes Dev. (2018) 32:126784. doi: $10.1101 /$ GAD. 314617.118 
130. Liu Y, Cao X. Immunosuppressive cells in tumor immune escape and metastasis. J Mol Med. (2016) 94:509-22. doi: 10.1007/s00109-015-1376-x

131. Dang CV. Links between metabolism and cancer. Genes Dev. (2012) 26:87790. doi: $10.1101 / \mathrm{gad} .189365 .112$

132. Dhup S, Kumar Dadhich R, Ettore Porporato P, Sonveaux P. Multiple biological activities of lactic acid in cancer: influences on tumor growth, angiogenesis and metastasis. Curr Pharm Des. (2012) 18:1319-30. doi: 10.2174/138161212799504902

133. Paul S, Lal G. The molecular mechanism of natural killer cells function and its importance in cancer immunotherapy. Front Immunol. (2017) 8:e1124. doi: 10.3389/fimmu.2017.01124

134. Pegram HJ, Andrews DM, Smyth MJ, Darcy PK, Kershaw MH. Activating and inhibitory receptors of natural killer cells. Immunol Cell Biol. (2011) 89:216-24. doi: 10.1038/icb.2010.78

135. Lanier LL. Up on the tightrope: natural killer cell activation and inhibition. Nat Immunol. (2009) 9:495-502. doi: 10.1038/ni1581.Up

136. Groh V, Wu J, Yee C, Spies T. Tumour-derived soluble MIC ligands impair expression of NKG2D and T-cell activation. Nature. (2002) 419:734-8. doi: $10.1038 /$ nature 01112

137. Harmon C, Robinson MW, Hand F, Almuaili D, Mentor K, Houlihan DD, et al. Lactate-mediated acidification of tumor microenvironment induces apoptosis of liver-resident NK cells in colorectal liver metastasis. Cancer Immunol Res. (2019) 7:335-46. doi: 10.1158/2326-6066.cir-18-0481

138. Husain Z, Huang Y, Seth P, Sukhatme VP. Tumor-derived lactate modifies antitumor immune response: effect on myeloid-derived suppressor cells and NK cells. J Immunol. (2013) 191:1486-95. doi: 10.4049/jimmunol.1202702

139. Bae EA, Seo H, Kim IK, Jeon I, Kang CY. Roles of NKT cells in cancer immunotherapy. Arch Pharm Res. (2019) 42:543-8. doi: 10.1007/s12272-019-01139-8

140. Xie D, Zhu S, Bai L. Lactic acid in tumor microenvironments causes dysfunction of NKT cells by interfering with mTOR signaling. Sci China Life Sci. (2016) 59:1290-6. doi: 10.1007/s11427-016-0348-7

141. Kumar A, Pyaram K, Yarosz EL, Hong H, Lyssiotis CA, Giri S, et al. Enhanced oxidative phosphorylation in NKT cells is essential for their survival and function. Proc Natl Acad Sci USA. (2019) 116:7439-48. doi: 10.1073/pnas. 1901376116

142. Gupta S. Role of dendritic cells in innate and adaptive immune response in human aging. Exp Gerontol. (2014) 54:47-52. doi: 10.1016/j.exger.2013.12.009

143. Steinman RM. The dendritic cell system and its role in immunogenicity. Annu Rev Immunol. (1991) 9:271-96. doi: 10.1146/annurev.iy.09.040191.001415

144. Kim B, Kim TH. Fundamental role of dendritic cells in inducing Th2 responses. Korean J Intern Med. (2018) 33:483-9. doi: 10.3904/kjim.2016.227

145. Deligeoroglou E, Giannouli A, Athanasopoulos N, Karountzos V, Vatopoulou A, Dimopoulos K, et al. HPV infection: immunological aspects and their utility in future therapy. Infect Dis Obstet Gynecol. (2013) 2013:540850. doi: 10.1155/2013/540850

146. Scott M, Nakagawa M, Moscicki AB. Cell-mediated immune response to human papillomavirus infection. J Allergy Clin Immunol. (2001) 8:209-20. doi: 10.1128/CDLI.8.2.209-220.2001

147. Leone P, Shin EC, Perosa F, Vacca A, Dammacco F, Racanelli V. MHC class $\mathrm{i}$ antigen processing and presenting machinery: organization, function, and defects in tumor cells. J Natl Cancer Inst. (2013) 105:1172-87. doi: 10.1093/jnci/djt184

148. Andersen MH, Schrama D, Thor Straten P, Becker JC. Cytotoxic T cells. J Invest Dermatol. (2006) 126:32-41. doi: 10.1038/sj.jid.5700001

149. Burnet M. Cancer; a biological approach. I. The processes of control. Br Med J. (1957) 1:779-86. doi: 10.1136/bmj.1.5022.779

150. Nasi A, Fekete T, Krishnamurthy A, Snowden S, Rajnavölgyi E, Catrina AI, et al. Dendritic cell reprogramming by endogenously produced lactic acid. $J$ Immunol. (2013) 191:3090-9. doi: 10.4049/jimmunol.1300772

151. Hsieh C, Macatonia S, Tripp C, Wolf S, O'Garra A, Murphy K. Development of TH1 CD4+ T cells through IL-12 produced by Listeriainduced macrophages. Science. (1993) 260:547-9. doi: 10.1126/science. 8097338

152. Wang KS, Frank DA, Ritz J. Interleukin-2 enhances the response of natural killer cells to interleukin-12 through up-regulation of the interleukin-12 receptor and STAT4. Blood. (2000) 95:3183-90. doi: 10.1182/blood.v95.10.3183.010k36_3183_3190

153. Gu Y, Yang J, Ouyang X, Liu W, Li H, Yang J, et al. Interleukin 10 suppresses Th17 cytokines secreted by macrophages and T cells. Eur J Immunol. (2008) 38:1807-13. doi: 10.1002/eji.200838331

154. Moore KW, de Waal Malefyt R, Coffman RL, O'Garra A. I Nterleukin-10 and the I Nterleukin-10 R eceptor. Annu Rev Immunol. (2001) 19:683-765. doi: 10.1146/annurev.immunol.19.1.683

155. Zhao S, Wu D, Wu P, Wang Z, Huang J, Gao JX. Serum IL-10 predicts worse outcome in cancer patients: a meta-analysis. PLOS ONE. (2015) 10:1-15. doi: 10.1371/journal.pone.0139598

156. Langowski JL, Zhang X, Wu L, Mattson JD, Chen T, Smith K, et al. IL-23 promotes tumour incidence and growth. Nature. (2006) 442:461-5. doi: 10.1038 /nature 04808

157. Shime H, Yabu M, Akazawa T, Kodama K, Matsumoto M, Seya T, et al. Tumor-secreted lactic acid promotes IL-23/IL-17 proinflammatory pathway. J Immunol. (2008) 180:7175-83. doi: 10.4049/jimmunol.180.11.7175

158. Fischer K, Hoffmann P, Voelkl S, Meidenbauer N, Ammer J, Edinger M, et al. Inhibitory effect of tumor cell-derived lactic acid on human T cells. Blood. (2007) 109:3812-9. doi: 10.1182/blood-2006-07-035972

159. Brand A, Singer K, Koehl GE, Kolitzus M, Schoenhammer G, Thiel A, et al. LDHA-associated lactic acid production blunts tumor immunosurveillance by T and NK cells. Cell Metab. (2016) 24:657-71. doi: 10.1016/j.cmet.2016.08.011

160. Daneshmandi S, Wegiel B, Seth P. Blockade of lactate dehydrogenase-A (LDH-A) improves efficacy of anti-programmed cell death-1 (PD-1) therapy in melanoma. Cancers. (2019) 11:450. doi: 10.3390/cancers 11040450

161. Calcinotto A, Filipazzi P, Grioni M, Iero M, De Milito A, Ricupito A, et al. Modulation of microenvironment acidity reverses anergy in human and murine tumor-infiltrating T lymphocytes. Cancer Res. (2012) 72:2746-56. doi: 10.1158/0008-5472.CAN-11-1272

162. Pilon-Thomas S, Kodumudi KN, El-Kenawi AE, Russell S, Weber AM, Luddy $K$, et al. Neutralization of tumor acidity improves antitumor responses to immunotherapy. Cancer Res. (2016) 76:1381-90. doi: 10.1158/0008-5472.CAN-15-1743

163. Colegio OR, Chu NQ, Szabo AL, Chu T, Rhebergen AM, Jairam V, et al. Functional polarization of tumour-associated macrophages by tumourderived lactic acid. Nature. (2014) 513:559-63. doi: 10.1038/nature13490

164. Lin S, Sun L, Lyu X, Ai X, Du D, Su N, Li H, Zhang L, Yu J, Yuan S. Lactate-activated macrophages induced aerobic glycolysis and epithelialmesenchymal transition in breast cancer by regulation of CCL5-CCR5 axis: a positive metabolic feedback loop. Oncotarget. (2017) 8:110426-43. doi: 10.18632/oncotarget.22786

165. Mu X, Shi W, Xu Y, Xu C, Zhao T, Geng B, et al. Tumor-derived lactate induces M2 macrophage polarization via the activation of the ERK/STAT3 signaling pathway in breast cancer. Cell Cycle. (2018) 17:428-38. doi: 10.1080/15384101.2018.1444305

166. Lambert AW, Pattabiraman DR, Weinberg RA. Emerging biological principles of metastasis. Cell. (2017) 168:670-91. doi: 10.1016/j.cell.2016.11.037

167. Walenta S, Schroeder T, Mueller-Klieser W. Lactate in solid malignant tumors: potential basis of a metabolic classification in clinical oncology. Curr Med Chem. (2012) 11:2195-204. doi: 10.2174/0929867043 364711

168. Matsumura A, Isobe $\mathrm{T}$, Takano S, Kawamura H, Anno I. Noninvasive quantification of lactate by proton MR spectroscopy and its clinical applications. Clin Neurol Neurosurg. (2005) 107:379-84. doi: 10.1016/j.clineuro.2004.10.009

169. Castagnoli L, Iorio E, Dugo M, Koschorke A, Faraci S, Canese R, et al. Intratumor lactate levels reflect HER2 addiction status in HER2-positive breast cancer. J Cell Physiol. (2019) 234:1768-79. doi: 10.1002/jcp.27049

170. Holohan C, Van Schaeybroeck S, Longley DB, Johnston PG. Cancer drug resistance: an evolving paradigm. Nat Rev Cancer. (2013) 13:714-26. doi: 10.1038/nrc3599

171. Amoedo ND, Obre E, Rossignol R. Drug discovery strategies in the field of tumor energy metabolism: limitations by metabolic flexibility and metabolic resistance to chemotherapy. Biochim Biophys Acta Bioenerg. (2017) 1858:674-85. doi: 10.1016/j.bbabio.2017.02.005 
172. Qu Y, Dou B, Tan H, Feng Y, Wang N, Wang D. Tumor microenvironmentdriven non-cell-autonomous resistance to antineoplastic treatment. Mol Cancer. (2019) 18:1-16. doi: 10.1186/s12943-019-0992-4

173. Apicella M, Giannoni E, Fiore S, Ferrari KJ, Fernández-Pérez D, Isella C, et al. Increased lactate secretion by cancer cells sustains non-cell-autonomous adaptive resistance to MET and EGFR targeted therapies. Cell Metab. (2018) 28:848-865.e6. doi: 10.1016/j.cmet.2018.08.006

174. DeBerardinis RJ, Chandel NS. Fundamentals of cancer metabolism. Sci Adv. (2016) 2:e1600200. doi: 10.1126/sciadv.1600200

175. Feng Y, Xiong Y, Qiao T, Li X, Jia L, Han Y. Lactate dehydrogenase A: a key player in carcinogenesis and potential target in cancer therapy. Cancer Med. (2018) 7:6124-36. doi: 10.1002/cam4.1820

176. Jafary F, Ganjalikhany MR, Moradi A, Hemati M, Jafari S. Novel peptide inhibitors for lactate dehydrogenase A (LDHA): a survey to inhibit LDHA activity via disruption of protein-protein interaction. Sci Rep. (2019) 9:1-13. doi: 10.1038/s41598-019-38854-7

177. Zhou Y, Tao P, Wang M, Xu P, Lu W, Lei P, et al. Development of novel human lactate dehydrogenase A inhibitors: high-throughput screening, synthesis, and biological evaluations. Eur J Med Chem. (2019) 177:105-15. doi: 10.1016/j.ejmech.2019.05.033

178. Kim EY, Chung TW, Han CW, Park SY, Park KH, Jang SB, et al. A novel lactate dehydrogenase inhibitor, 1-(phenylseleno)-4-(trifluoromethyl) benzene, suppresses tumor growth through apoptotic cell death. Sci Rep. (2019) 9:1-12. doi: 10.1038/s41598-019-40617-3

179. Das CK, Parekh A, Parida PK, Bhutia SK, Mandal M. Lactate dehydrogenase A regulates autophagy and tamoxifen resistance in breast cancer. Biochim Biophys Acta Mol Cell Res. (2019) 1866:1004-18. doi: 10.1016/j.bbamcr.2019.03.004

180. Fang A, Zhang Q, Fan H, Zhou Y, Yao Y, Zhang Y, Huang X. Discovery of human lactate dehydrogenase A (LDHA) inhibitors as anticancer agents to inhibit the proliferation of MG-63 osteosarcoma cells. MedChemComm. (2017) 8:1720-6. doi: 10.1039/c7md00222j

181. Manerba M, Di Ianni L, Govoni M, Roberti M, Recanatini M, Di Stefano G. LDH inhibition impacts on heat shock response and induces senescence of hepatocellular carcinoma cells. Eur J Pharm Sci. (2017) 105:91-8. doi: 10.1016/j.ejps.2017.05.015

182. Curtis NJ, Mooney L, Hopcroft L, Michopoulos F, Whalley N, Zhong H, et al. Pre-clinical pharmacology of AZD3965, a selective inhibitor of MCT1: DLBCL, NHL and Burkitts lymphoma anti-tumor activity. Oncotarget. (2017) 8:69219-36. doi: 10.18632/oncotarget.18215

183. Guan X, Rodriguez-Cruz V, Morris ME. Cellular uptake of MCT1 inhibitors AR-C155858 and AZD3965 and their effects on MCT-mediated transport of L-lactate in murine 4T1 breast tumor cancer cells. AAPS J. (2019) 21:5. doi: $10.1208 /$ s12248-018-0279-5
184. Amorim R, Pinheiro C, Miranda-Gonçalves V, Pereira H, Moyer MP, Preto A, et al. Monocarboxylate transport inhibition potentiates the cytotoxic effect of 5-fluorouracil in colorectal cancer cells. Cancer Lett. (2015) 365:68-78. doi: 10.1016/j.canlet.2015.05.015

185. Quanz M, Bender E, Kopitz C, Grünewald S, Schlicker A, Schwede W, et al. Preclinical efficacy of the novel monocarboxylate transporter 1 inhibitor BAY-8002 and associated markers of resistance. Mol Cancer Ther. (2018) 17:2285-96. doi: 10.1158/1535-7163.MCT-17-1253

186. Benjamin D, Robay D, Hindupur SK, Pohlmann J, Colombi M, El-Shemerly MY, et al. Dual inhibition of the lactate transporters MCT1 and MCT4 is synthetic lethal with metformin due to NAD+ depletion in cancer cells. Cell Rep. (2018) 25:3047-3058.e4. doi: 10.1016/j.celrep.2018.11.043

187. Ciocca DR, Calderwood SK. Heat shock proteins in cancer: diagnostic, prognostic, predictive, and treatment implications. Cell Stress Chaperones. (2005) 10:86-103. doi: 10.1379/csc-99r.1

188. Zhao YH, Zhou M, Liu H, Ding Y, Khong HT, Yu D, et al. Upregulation of lactate dehydrogenase A by ErbB2 through heat shock factor 1 promotes breast cancer cell glycolysis and growth. Oncogene. (2009) 28:3689-701. doi: 10.1038/onc.2009.229

189. La Manna S, Di Natale C, Florio D, Marasco D. Peptides as therapeutic agents for inflammatory-related diseases. Int J Mol Sci. (2018) 19:1-18. doi: 10.3390/ijms19092714

190. Henninot A, Collins JC, Nuss JM. The current state of peptide drug discovery: back to the future? J Med Chem. (2018) 61:1382-14. doi: 10.1021/acs.jmedchem.7b00318

191. Kurrikoff K, Aphkhazava D, Langel Ü. The future of peptides in cancer treatment. Curr Opin Pharmacol. (2019) 47:27-32. doi: 10.1016/j.coph.2019.01.008

192. Murray CM, Hutchinson R, Bantick JR, Belfield GP, Benjamin $\mathrm{AD}$, Brazma D, et al. Monocarboxylate transporter Mctl is a target for immunosuppression. Nat Chem Biol. (2005) 1:371-6. doi: $10.1038 /$ nchembio744

Conflict of Interest: The authors declare that the research was conducted in the absence of any commercial or financial relationships that could be construed as a potential conflict of interest.

Copyright (c) 2019 de la Cruz-López, Castro-Muñoz, Reyes-Hernández, GarcíaCarranca and Manzo-Merino. This is an open-access article distributed under the terms of the Creative Commons Attribution License (CC BY). The use, distribution or reproduction in other forums is permitted, provided the original author(s) and the copyright owner(s) are credited and that the original publication in this journal is cited, in accordance with accepted academic practice. No use, distribution or reproduction is permitted which does not comply with these terms. 